\title{
الخصوصيات الثقافية في ظل إعلام العولمة بين ثقافة الأصالة وثقافة الحداثة
}

\section{السعيد سليمان عواشرية}

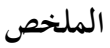

تبحث الورقة في التحدي الذي يمثلة إعلام العولمة للخصوصيات الثقاقية لبلدان العالم بصفة عامة والبلدان

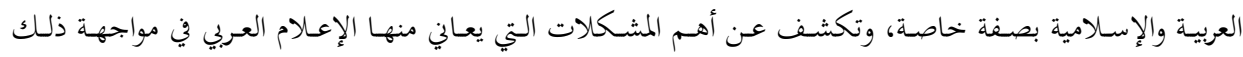

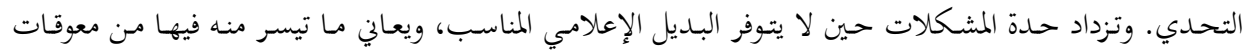

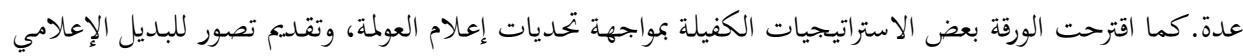

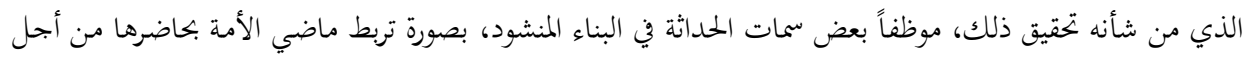

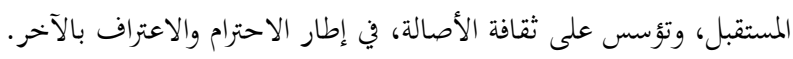
الكلمات المفتاحية: الثقافة، الخصوصيات الثقافية، إعلام العولمة، الأصالة، الحداثة.
\end{abstract}

\section{Cultural specificities in light of media globalization between culture of originality and culture of modernity}

Abstract

The paper examines the challenge posed by the globalization of the media to the cultural specificities of the countries of the world in general and the Arab and Islamic countries in particular. It reveals the problems of the Arab and Muslim media in facing that challenge.The problems become more acute when there is no appropriate media alternative, and with presence of the constraints that limit the function of what is available.

The paper also suggests some strategies to meet the challenges of media globalization, an introduce and alternative media that employs some attributes of modernity, links the nation past with its present to build its future, and establish a culture of authenticity in a framework of respect and recognition of the other.

Keywords: Culture, Cultural specificities, Media globalization, authenticity, Modernity.

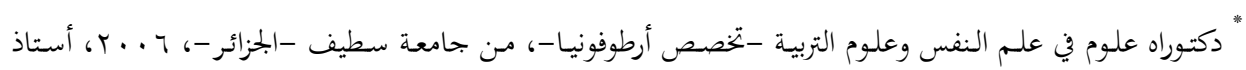

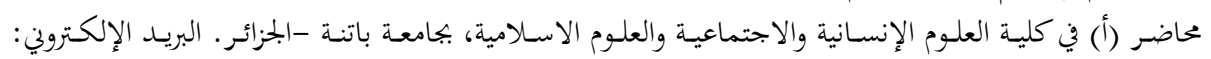

$$
\begin{aligned}
& \text { rimasma2012@yahoo.fr }
\end{aligned}
$$

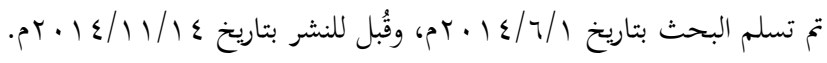




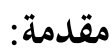

نظراً لكون وسائل الإعلام تقدم قدراً كبيراً من المعلومات عن العالمه وعن أمور لا نستطيع أن نعلم بها على نحو مباشر، فإها تصبح مناسبة أكثر للتأثير فينا، لأهفا تضيف المزيد لتصورنا للواقع، وتؤثر بقوة في الطريقة التي نبني بها أجزاء من الظروف المحيطة بنا، بصورة قد لا تتوافق مع هويتنا الثقافية في ضوء ما تقدمه من برامج، خاصة في ظل بروز العولمة الثقافية، وهو الذي أيقظ المفكرين، والباحثين من أجل تدارك مخاطرها، والاستفادة من حداثتها بما لا يشكل خطراً على الأصالة العربية الإسلامية.

إن الاختراق الثقافي يكرّس منظومة معينة من القيم الوافدة التي تسري ببطء وثبات

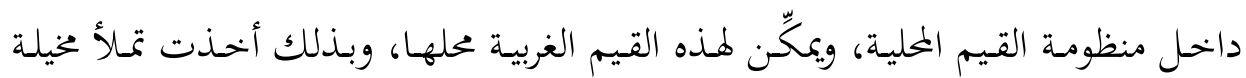
هؤلاء بأبطال ورموز جديدة، بدءاً بعارضات الأزياء وبنحوم الكرة، وصولاً إلى رموز الفن ولن

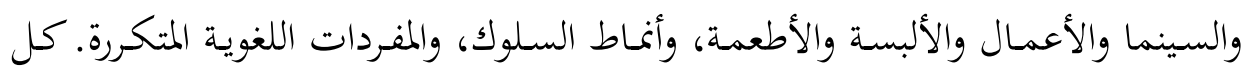

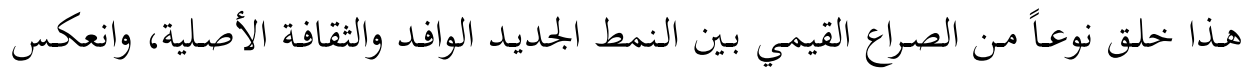
تأثيره على شخصية الطفل العربي، حتى أصبحت تظهر عليه علامات الازدواج في سلوكه

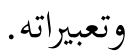

ويأتي طرحنا هذا استناداً إلى استقرائنا لبعض جوانب الواقع العربي، التي توحي بأن مُثُلَنَا العليا لمُ تَعُدْ هي العمل، والرقي، والعروبة، والإسلام، والثقافة الرفيعة، بل صارت ثقافة استهلاكية، تتلخص في أقذر ما ينتجه الغرب من أفكار وممارسات. إن شخصيات وتروبهات

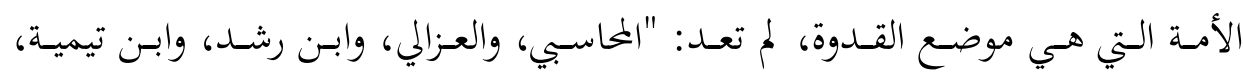
وصلاح الدين الأيوبي" بل غدت تلك شخصيات "هوليود" ذات الرؤية الغربية. ومسن هنا يمكن القول إن الوضع الذي آل إليه العرب والمسلمون، وشكَّل صورةهم المتداولة في العالم قد يكون جزءٌ منه نتيجة للإعلام العربي، سواء لأنه لم يؤدِّ وظيفته كما

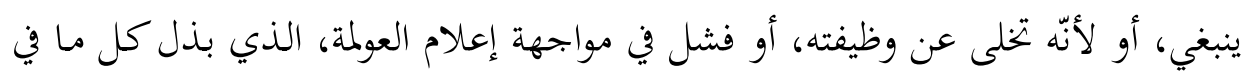




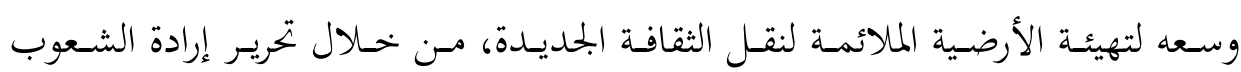

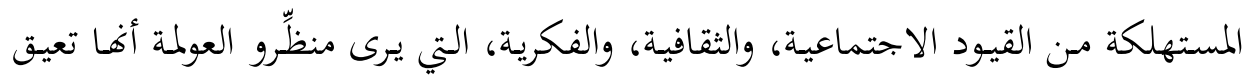

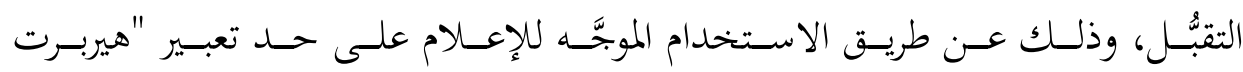
شيللر 'Herbert Schiller.

لقد غدا الإقبال على الثقافة المستوردة - كما يرى بعض المفكرين - غير ناجز إلا

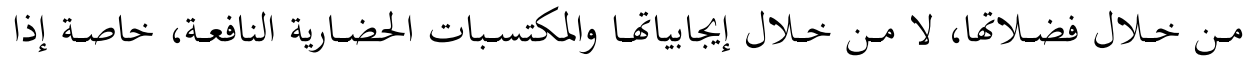

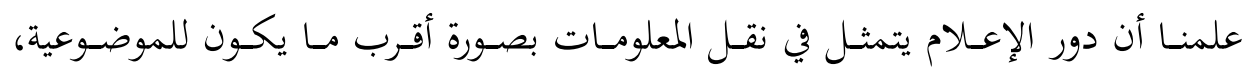
والحيادية، غير أنه يعكس المضامين الثقافية التي تشكل خلفية وكالات الأنباء التي يسيطر عليها الغرب، وهذا لا ينفي المجهودات المبذولة، والنتائج الإيجابية لبعض محاولات الإعلام

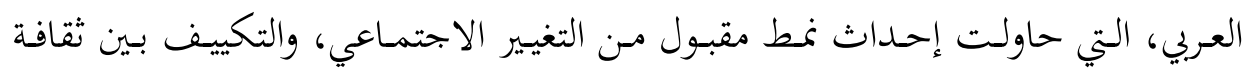
الأصالة وثقافة الحداثة. وهذا دليل على أن الإعلام العربي قادر على بناء الحداثة الثقافية

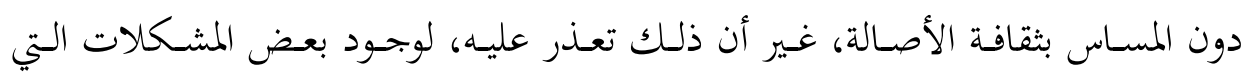
حالت بينه، وبين تحقيق ذلك، خاصة في ظل إعلام العولمة، وهنا نتساءل:

$$
\text { - ما سمات إعلام العولمة، وأهدافه؟ }
$$

- ما أثر إعلام العولمة في الخصوصيات الثقافية العربية في ظل الإعلام العربي العاجز عن المواجهة؟

- ما المشكلات التي تواجه الإعلام العربي في حماية النسيج الاجتماعي للأمة العربية

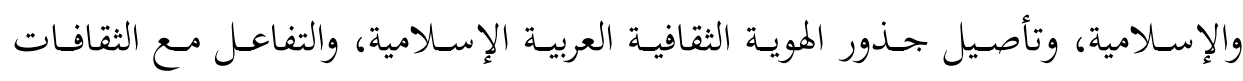
الأخرى في ظل إعلام العولمة؟

- مـا السـبل الكفيلـة بـالخروج مـن تلـك المشـكات وجعـل الحمداثـة طريقـا للبنـاء

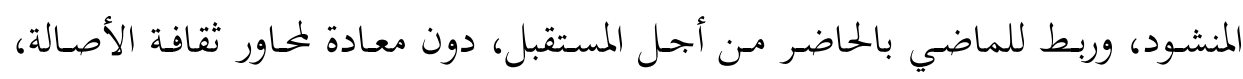
وذلك في إطار الاحترام، والاعتراف بالآخر؟

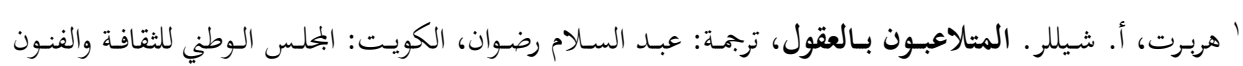

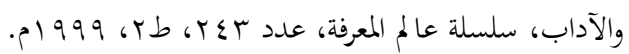


أولاً. ضبط المفاهيم

\section{ا ـ الخصوصية الثقافية:}

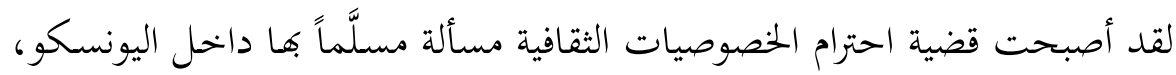

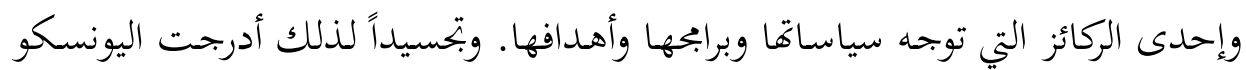

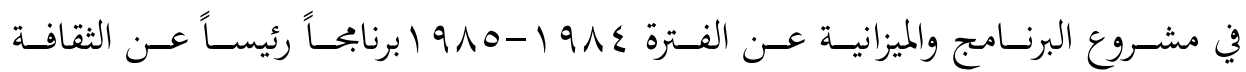

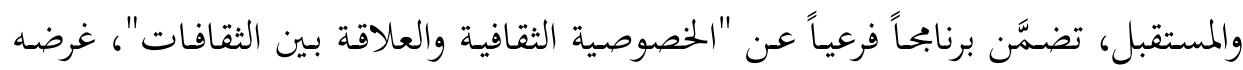

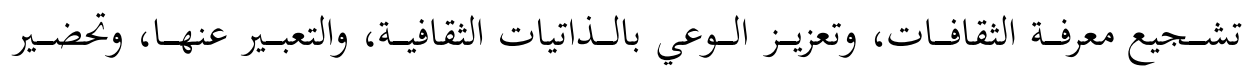

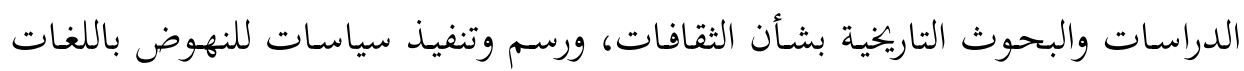

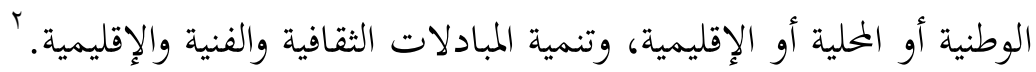

ومن هذا المنطلق حاولت أوروبا، وعلى رأسها فرنسا -من أجل الدفاع عن موقعها

في السـوق - أن تطرح مبـدأ الخصوصية الثقافـة، غـير أن هـذا الطـرح لم يهقـق إلا بناحـاً جزئياً، تمثل في الحصول على الموافقة على مبدأ التعامل الخاص المحدود في بحال الإنتاج السمعي والمرئي.

ويمكن تعريف الخصوصية الثقافية بأفها نتـاج تفاعل بحموعة مـن المكونات المتمثلة

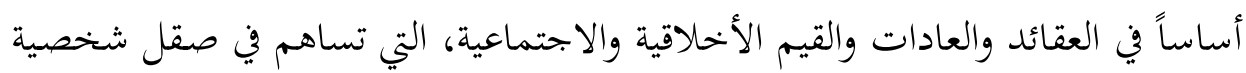

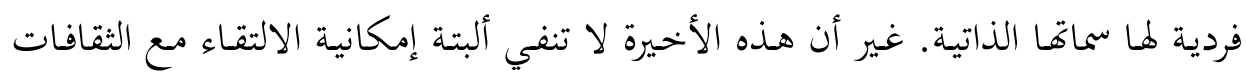
الأخرى في بعض العناصر.

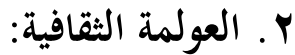

لقد ارتبط المفهوم الثقافي للعولمة بفكرة التنميط أو التوشُّد الثقافي للعالم، على حدّ

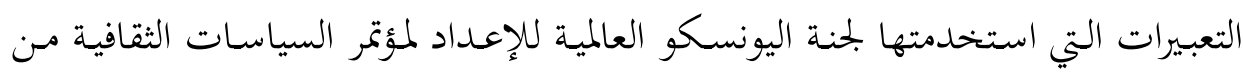

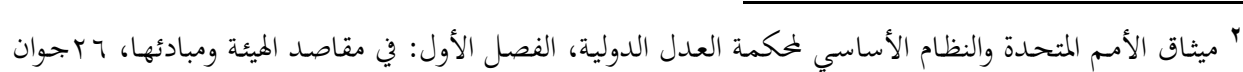

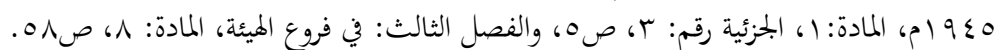

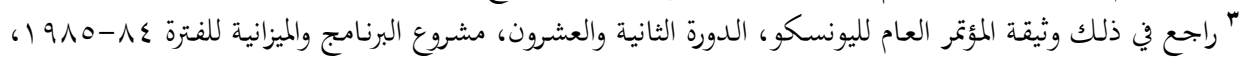


أجل التنمية، التي عقدت اجتماعاتا في مدينة استكهولم عام 991 1؛ إذ رأت اللجنة أن التنمسيط الثقـافي يـم باستغلال ثـورة وشـبكة الاتصـالات العالميـة، وهيكلهـا الاقتصـادي

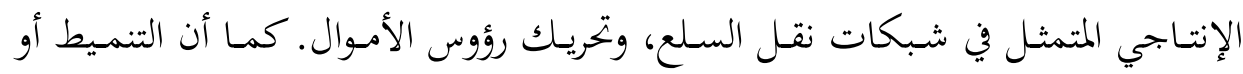
التوحّد الثقافي هو مرآة التطور الاقتصادي للعولمة. ؛

وهو ما يؤدي إلى تسليع الثقافة؛ إذ تصبح الثقافة التي لا تعتمد على منطق السوق مهادة في وجودها وبقائها؛ لأن منطق السوق يقتضي توفر القدرة على الاستثمار، وهو ما لا تملكه الدول النامية. ْومن ثمّ تصبح بحرد سوق لاستهالاك الثقافة الواحدة، التي هيأ لها إعلام العولمة الأرضية الملائمة للتقبّل، بالتأثير على أول مصنع لما ألا وهي الأسرة، من

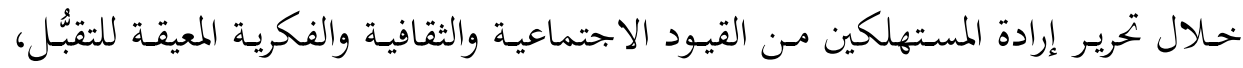
بالاستخدام الموجه للكلمة والصورة. إن تعـد الثقافـات مـن وجهة نظر دعـاة العولمة هي السبب الرئيس للانقسـام بـين

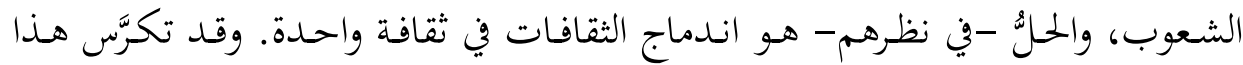

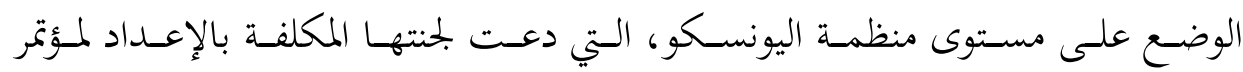

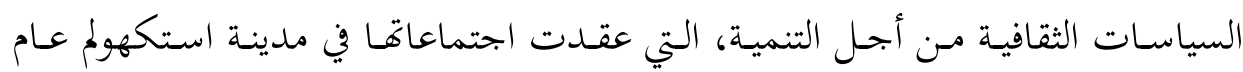
1991 برئاسة "خافيير بيريز دي كويلار" Javier Pérez de Cuéllar الأمين العام السابق للأمم المتحدة، إلى فكرة التوحيد الثقافي بوصفها مرآة التطور الاقتصادي للعولمة. v ولا شـك في أن هـذا الإقرار على مستوى منظمـة بحجــم اليونسـكو يحمـل خطورة

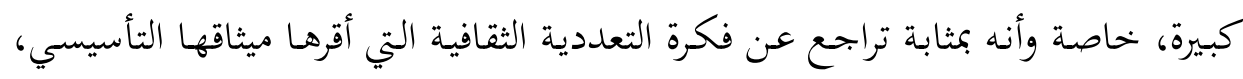

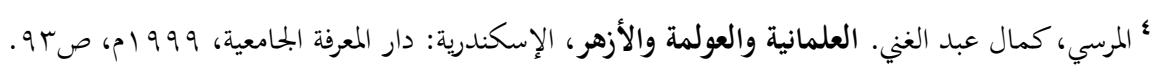
انظر أيضاً:

- بوجلال، عبد الله. "إثكالية الوفرة الإعلامية والمعلوماتية في ظل العولمة"، مجلة الحقيقة، جامعة أدرار، الجزائر،

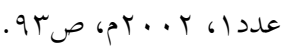
• بلقزيز ، عبد الإله. "العولمة والموية الثقافية: عولمة الثقافة أم ثقافة العولمة"، مجلة المستقبل، مركز دراسات الوحدة

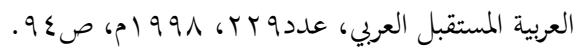

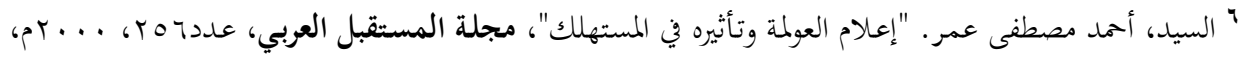




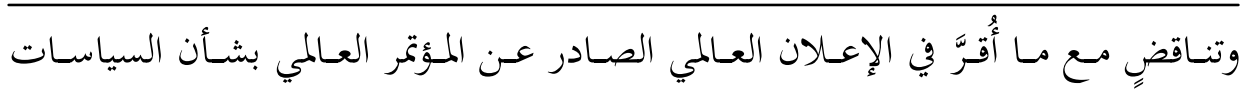

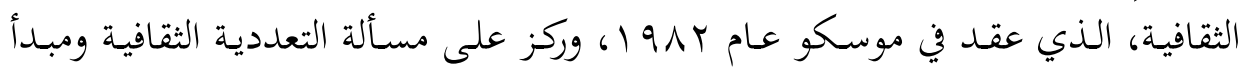
احترام الخصوصيات الثقافية، وما موقف اليونسكو آنذاك من إعادة كتابة "تاريخ التطور

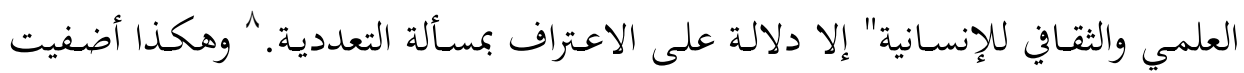

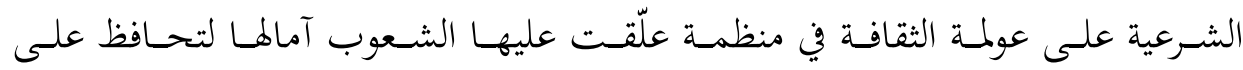
خصوصياتما الثقافية وتعزيزها.

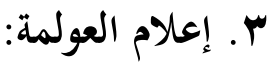

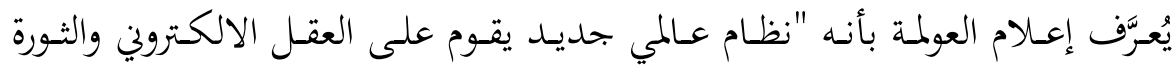

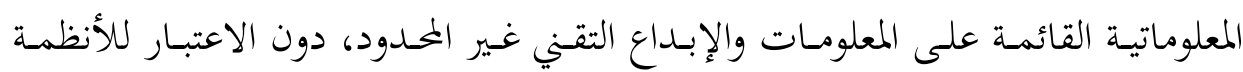

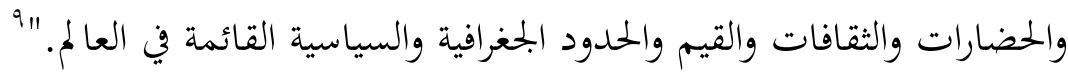

ويعرَّف -أيضـاً- بأنـه "سـلطة تكنولوجيـة ذات منظومـات معقـدة لا تلتزم بالحـدود

الوطنية للدول، وإنما تطرح حدوداً فضائية غير مرئية، ترسمها شبكات اتصالية معلوماتية على أسس سياسية واقتصادية وثقافية وفكرية، لتقيم عالماً من دون دولة، ومن دون أمة، ومسن دون وطن ليحلّ مكانه عالم المؤسسات والشبكات التي تتمركز وتعمل تحت إمرة منظمـات ذات طبيعـة خاصـة وشـركات متعـددة الجنسـيات، يتسـمم مضـمونه بالعالميـة والتوحّد، على الرغم من تنوع رسائله التي تبث عبر وسائل تتخطى حواجز الزمان والمكان واللغة، لتخاطب مستهلكين متعددي المشارب والعقائد والرغبات والأهواء." ·ل

\section{ع. الحداثة:}

يؤرخ بعض المفكرين بداية الحداثة عام ب؟ع ا، باختراع غوتنبيرغ للطباعة المتحركة، ويرى آخرون أها بدأت منذ العام . به إمع الثورة اللوثرية ضد سلطة الكنيسة. بجموعة

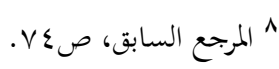
9 "نافعة، حسن، "اليونسكو وقضايقايا التعددية الثقافية والحضارية (رؤية عربية)"، مجلة السياسة الدولية، مصر، مؤسسة

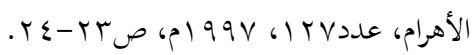

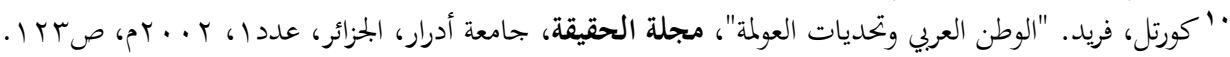


أخرى من المؤرخين يتقدمون بها إلى العام یـ؟ ا مع فهاية حرب الثلاثين عام، وبحموعة

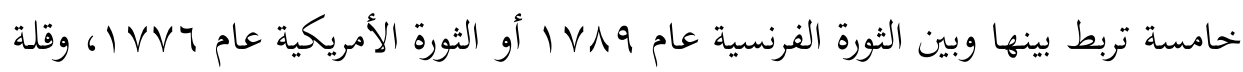

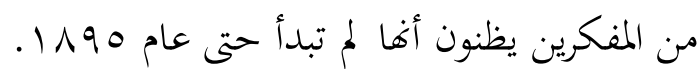

جـاء في موســوعة يونيفارسـاليس: "تعـــ تحــولات البـنى السياسـية والاقتصـادية والتكنولوجية والنفسية العوامل التاريخية الموضوعية لظهور الحداثة، فهذه التحولات ليست هي الحداثة في حد ذاتها... فالحداثة ليست هي الثورة الصناعية والتكنولوجية، وركنها إدخال لمذه الثورة في مسرح الحياة الشخصية والاجتماعية."

فالحداثـة في جوهرهـا خصوصية غربية بمـا حملته حضـارة وإنسـان يعيشـان حالة مـن الأزمة بسبب التطور العلمي والفكري الذي استمر طوال ثلاثة قرون من الزمن، وهو ما جعل السـمة الأساسية للحداثة في أهـا ميّزت المجتمع الغربي الحـديث، وما يطلق عليها بالتجاوز المستمر . ويمكن لنا القول إن الحداثة الغربية احتوت القيم الآتية: أ. التمرد على القوانين وطرق التعبير والتقاليد الفنية المألوفة.

ب. تحرير الفرد مـن سلطة المؤسسـات بكل أنواعها، ومسن ضمنها مؤسسة الأسرة التي تعـد في نظرهـا صـورة مـن صسور القهـر، مـع مـا يعنيـه ذلك مـن إخـراج العلاقـة بـين

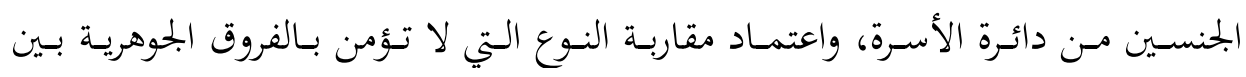
الجنســن، وتـدعو إلى حـق الشـذوذ الـذي يصـل إلى المطالبـة بحـق الـزواج المثلـي (الـذي صادقت عليه بجموعة من الدول الأوروبية انسجاماً مع هذا المفهوم الجمديد للحرية). تـ إلغـاء المعتى المسـبق في النصـوص، بمـا فيهـا النصـوص الدينيـة وربـط الدلالــة

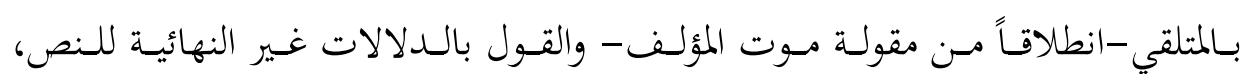
وتكريس مذهب الشك في كل الحقائق والمفاهيم. ث. اعتبار الدين بتربة بشرية قابلة للتجاوز ضمن ما تتجاوزه الحداثة، وإلغاء سلطته من خلال علمنة البحتمع، وإلغاء سلطة الأخلاق في بحال الإبداع. 
ج. تمجيد التجارب المتأخرة زمنياً والمبالغة في التمرد داخل كل مذهب.

ح. تمجيد العقلانية والتفكير العقلاني، ووضعه في مقابل التفكير الديني، واعتبار هذا

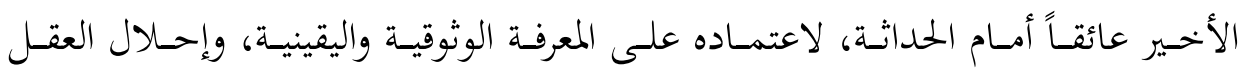
ومنجزاته العلمية محل الله في مركزية البحتمع. خ. تمجيد الجسد والارتفاع به إلى مستوى التقديس. د. التعبير عن مفـاهيم تعكس وضعية التشرذم والأزمة التي يعيشها الإنسان الغربي، كمفاهيم الغربة واليأس والضياع.

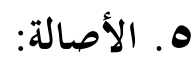
يقتضي فهم الأصالة ما يلي: - ضـرورة معرفـة ثقافتنـا وفهمها: وفهـم هـذه الثقافـة لا بـدّ أن يكون مـن مصـادرها الأصلية، ومن أهلها الثقات، وبأدواقا ومناهجها الخاصة.

- الاعتزاز بالانتماء العربي الإسلامي: يشعر المثقف العربي المسلم، الذي ينتمي إلى ثقافة العرب والمسلمين، أنه عضو في جسم هذه الأمة، وأنه متحرر من عقدة النقص التي يعاني منها بعض الناس تجاه كل ما هو غربي. إنه يعتز بلغته؛ لغة القرآن وبالعلوم، ويعمل على أن تكون لغة الحياة، ولغة العلم، ولغة الثقافة، وقد كانت لغة العلم الأولى في العالم كله لعدة قرون، فلا يجوز أن تعجز اليوم عمّا قامت به بالأمس.

- العودة إلى الأصول: أعني أصولنا وجذورنا العقدية والفكرية، والأخلاقية، والسعي إلى تحويل اعتزازنا النظري والعاطفي إلى سلوك عملي. إن الاعتزاز يصبح ظاهرة مرضيَة

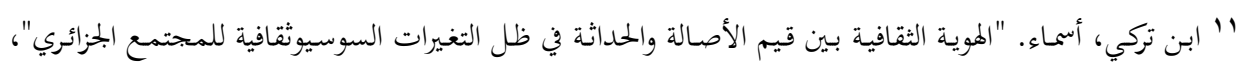

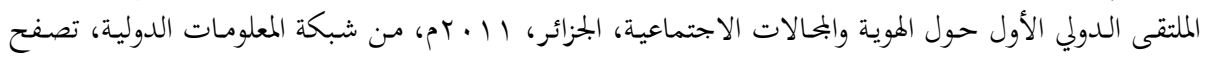

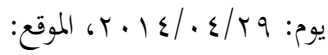
- http://manifest.univ-ouargla.dz/index.php/seminaires/archive/facult\%C3\%A9-dessciences-sociales-et-sciences-humaines/53. 
إذا ظل بحرد كـلام يـتردَّد، وشعارات تُرفع، وصـيحات تتعـالى، لسرد الأبحاد، وتعظيم

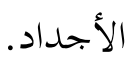

- الانتفاع الواعي بتراثنا والغوص في حضنه الزاخر، لاستخراج جواهره. ولا يتصور

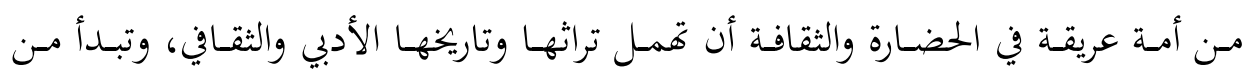
الصفر، أو من التسول لدى غيرها.

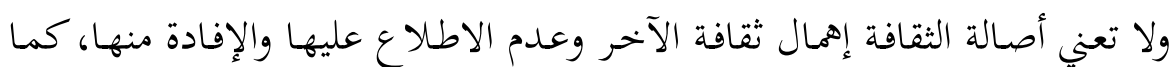

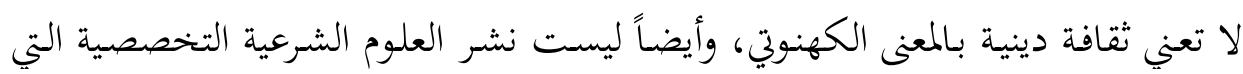

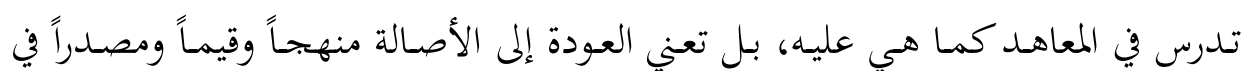

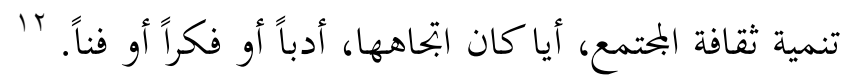

ثانياً: الخصوصيات الثقافية وتحديات إعلام العولمة

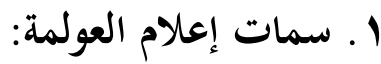

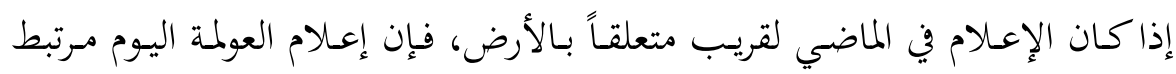

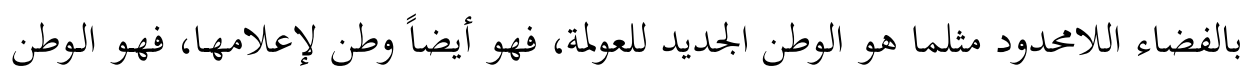

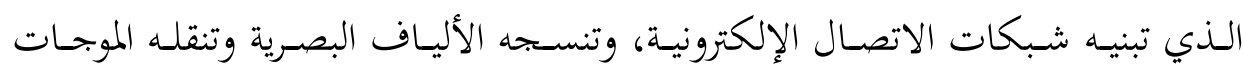

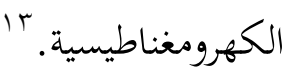

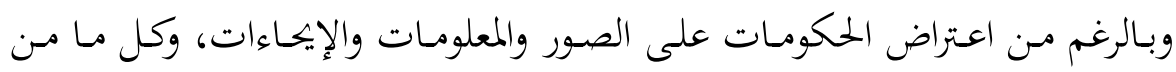

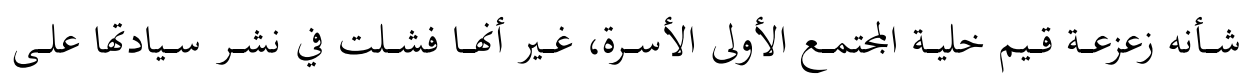

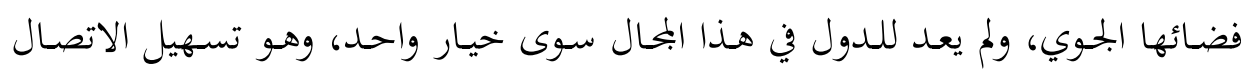
وسريان الإعلام لفائدة الشبكات العالمية.

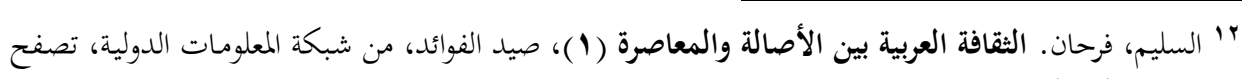
- http://www.saaid.net/Minute/158.htm.

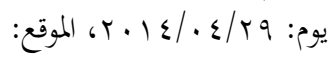

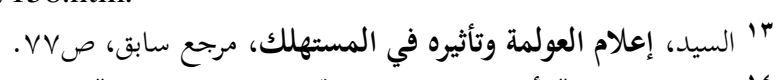

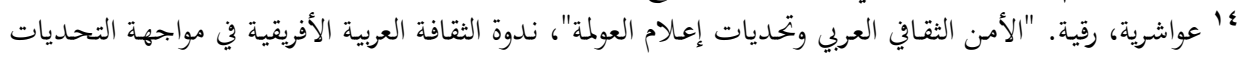

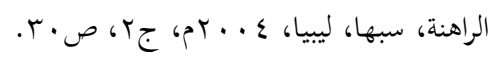


ويمكن تلخيص أهم سمات إعلام العولمة في ما يلي:

أ. إعلام متقدم من الناحية التكنولوجية، ومؤهل لتطورات مستقبلية جديدة ومستمرة تدفع به إلى المزيد من الانتشار المؤثر في المحتمعات المختلفة. ب. يشكل جزءاً مـن البنية السياسية الدولية الجديدة، التي تطرح مفـاهيم جديدة لسيادة الدولة على أراضيها وشواطئها وفضائها الخارجي. ت. يشكل جزءاً من البنية الاقتصادية العالمية التي تفرض على الكل أن يعمل ضمن شروط السوق السائدة من صراعات ومنافسات وتكتلات، وسعي متصل لتحقيق الربح للمؤسسات التي تحتكره بحكم انتمائها إلى أكثر من وطن، وعملها في أكثر من بحال، بما في ذلك صناعة السلاح وبتحارته.

ث. يشكل جزءاً من البنية الثقافية للمجتمعات التي تنتجه وتوجهه وتتوجه به، ولذذا فإنه يسعى إلى نشر وشيوع ثقافة عالميـة، تعرف عند مصدرها بالانفتـاح الثقافي، وعند متلقيها بالغزو الثقافي.

ج. يشكل جزءاً من البنيـة الاتصـالية الدولية التي مكنّته من تحقيق عولمته، وعولمـة رسائله ووسائله، فهو ينتمي إلى أحد حقول التكنولوجيا الأكثر تطوراً في الوقت الراهن والمحتكر ح. لا يسـتند إلى فـراغ، فثمـة اتفاقيـات دوليـة تـدعمها منظمـات وقـرارات تحـدد

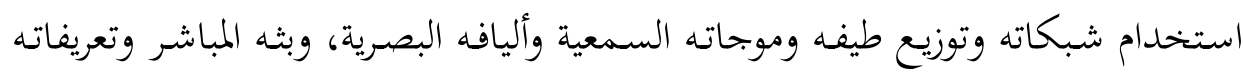
الجمركية للصحف والمحلات والكتب والأشرطة.

خ. لا يشكل نظاماً دولياً متوازياً، لأن كل مدخلاته ومراكز تشغيله وآليات التحكم

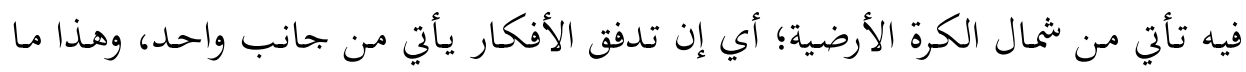
أدى إلى هيمنة الدول المتقدمة عليه دون الدول النامية. 


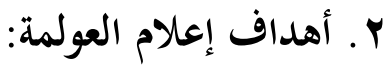

ومما لا شك فيه أن هذه السمات ستؤثر بدرجة ما في الخصوصية الثقافية للدول،

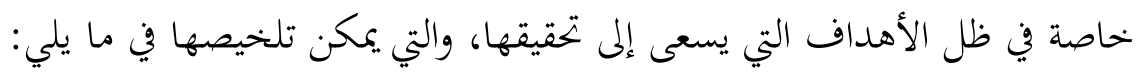

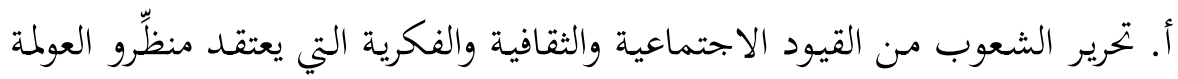

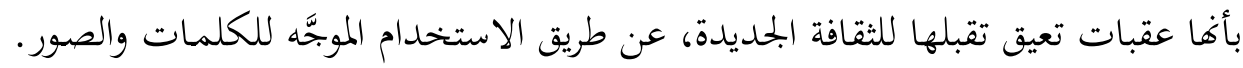

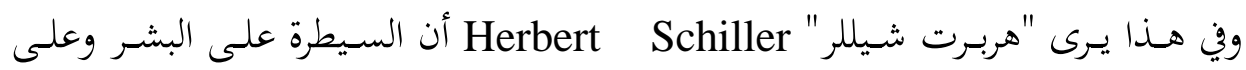

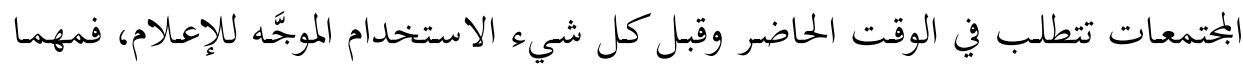

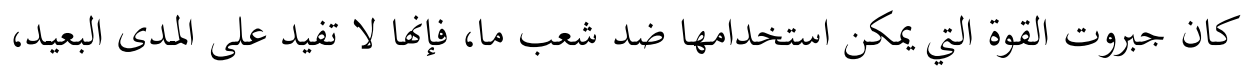

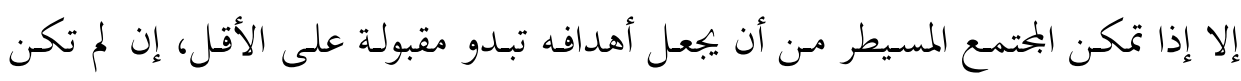
جذابة للمستهادفين.

ب. تعويد العقول على معايشة الأنماط المغرية للثقافة المحديدة ومشاهدها، بإحكام

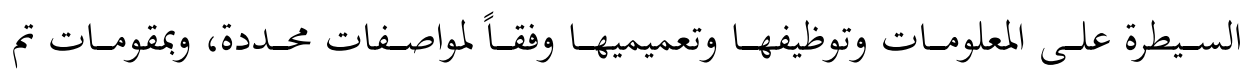

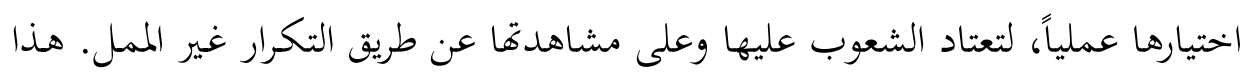

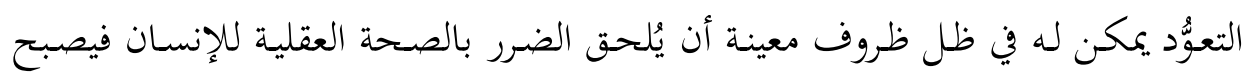

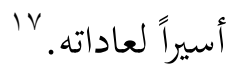

ت. إعادة تشكيل الحياة الاجتماعية للشعوب على نمط الحياة الغربية، وحثها على فئل

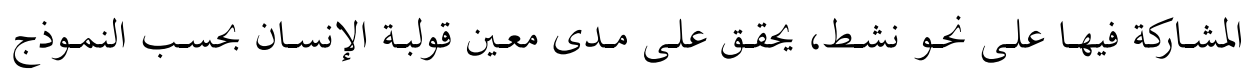

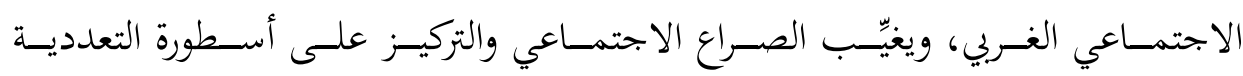

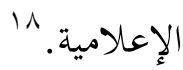

ث. تعزيز فكرة الانخراط النشط في الثقافة الجحديدة، عن طريق إبراز مظهرها الخارجي

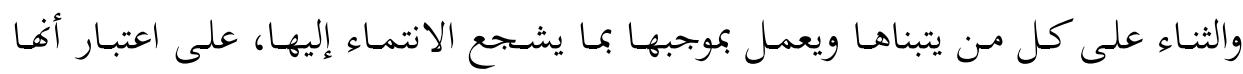

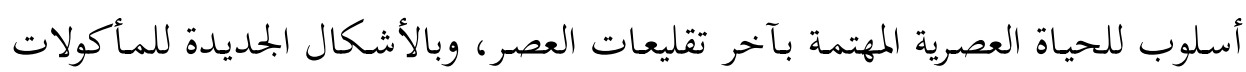

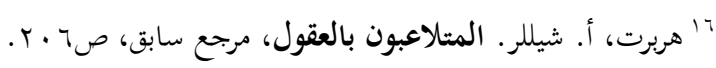

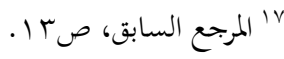

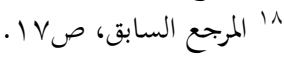


والمشروبات والملبوسات والمتعة والترفيه، والإنفاق في إطار يتجاوب مع الرأسمالية إلى زيادة

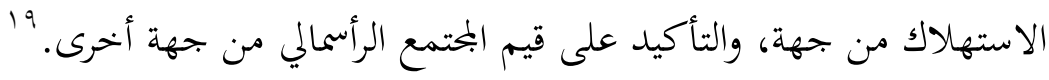

\section{r. تأثير إعلام العولمة في الخصوصيات الثقافية:}

ينظر بعض البـاحثين إلى إعلام العولمة نظرة إيبابية مـن حيـث إنه يسهم في إثراء

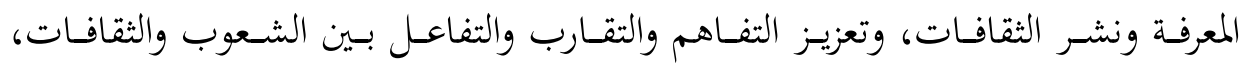

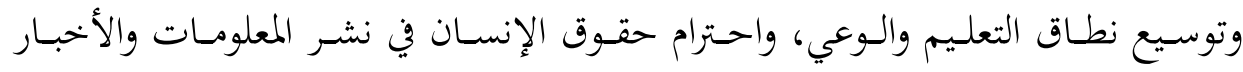

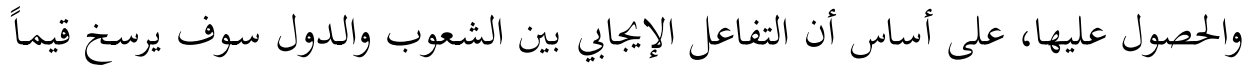

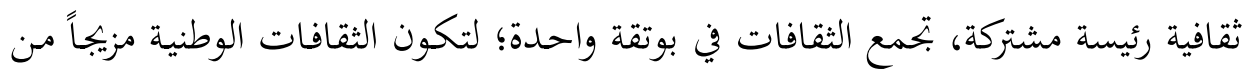
ثقافة دولية تحترم المعاصرة، وثقافة محلية تحافظ على الأصول والمنابع. في حين ينظر آخرون إليه على أنه هيمنة ثقافية، وتسلط على عقول الأفراد؛ ‘ أي

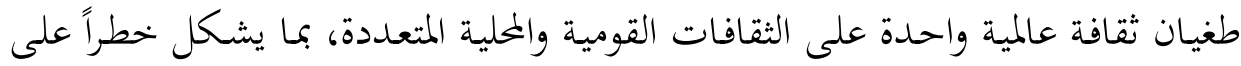

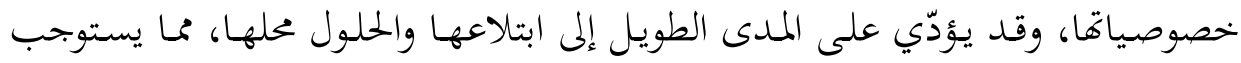

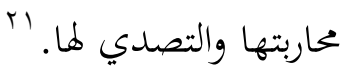

فإذا كان الصراع الإيديولوجي ولا يزال يستهدف تشكيل الوعي، سواء بتزييفه أو تصحيحه، فإن الاختراق الثقافي المعاصـر يستهدف السيطرة على الإدراك مـن خهلال

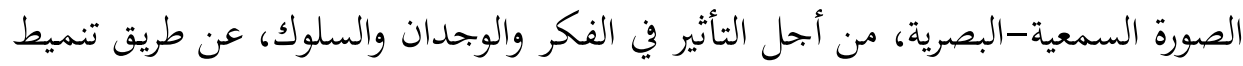

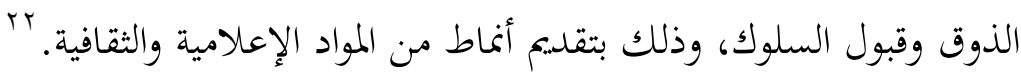

فإعلام العولمة يتضمن بلوغ البشرية مرحلة لانتقال الأفكار والمعلومات والبيانات

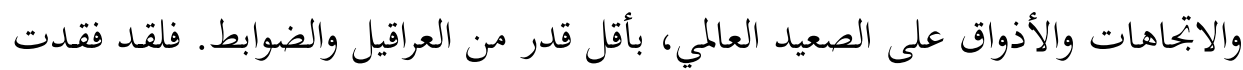

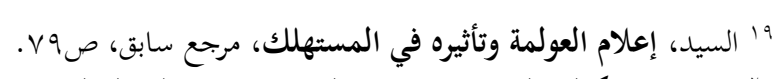

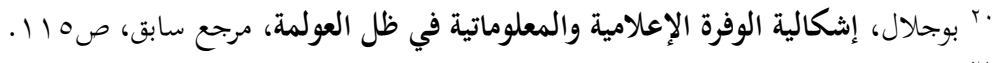

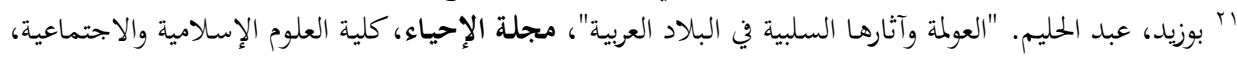

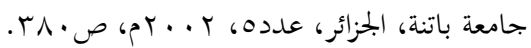
r r عبد الرمن،، عواطف. "الإعلام العربي بين غياب الديمقراطية والاختراق الثقافي"، مجلة الدراسات الإعلامية، 
الدول في ظله القدرة على التحكم في تدفق المعلومات والأفكار والقيم والقناعات في مـا

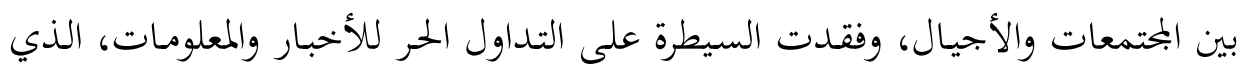

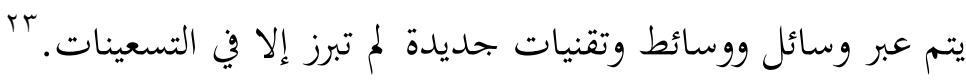

لقد حرصت الحكومة الفرنسية مثلاً على مدّ الشبكات الإذاعية وأطياف الترددات

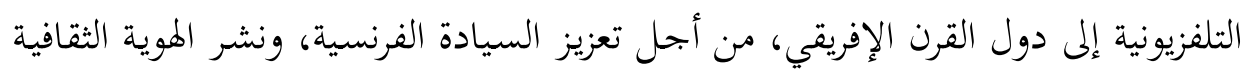

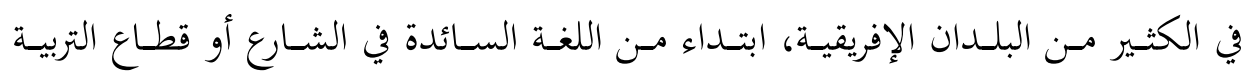

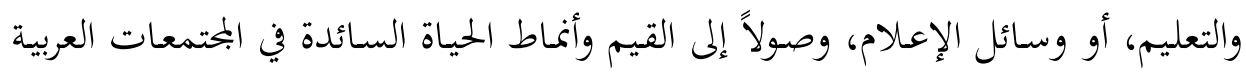

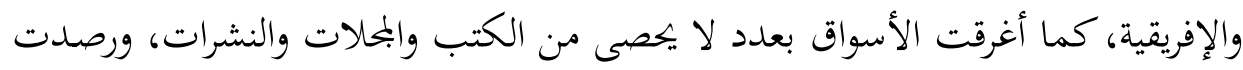

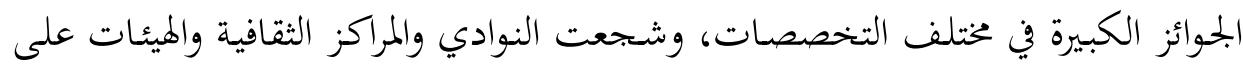

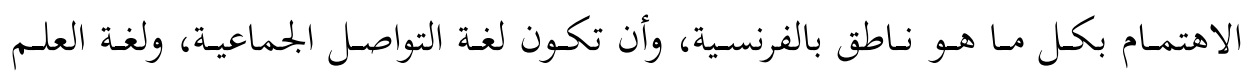

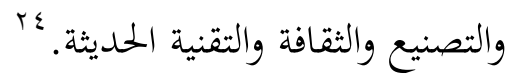

والملاحظ أن الولايات المتحدة الأمريكية قامت بشكل كبير من أجل ضرب المصالح

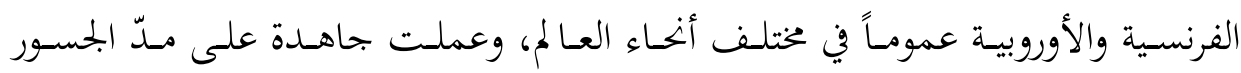

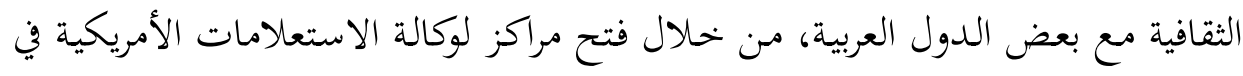
بعض الدول، كمصر وتونس والمغرب وجنوب إفريقيا وكينيا وتنزانيا، وصارت هذه المراكز

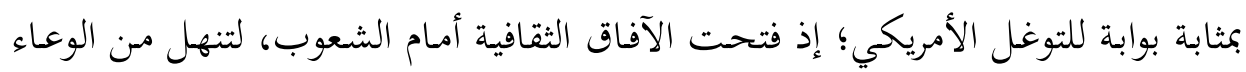

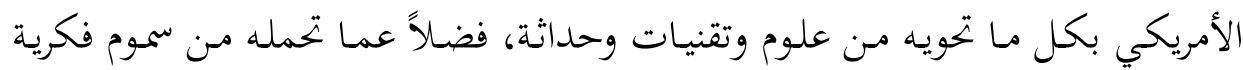

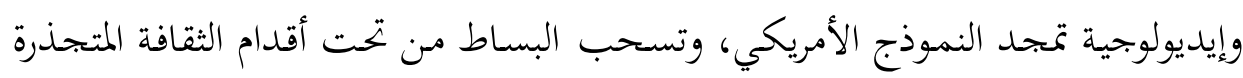

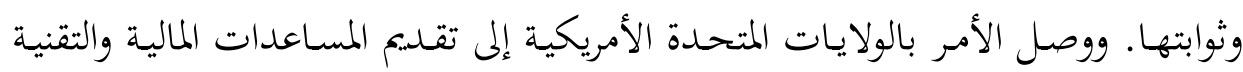

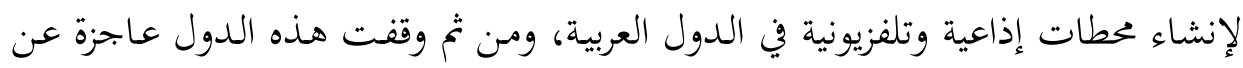
"r بركات، عمدد مراد. "تأملات نقدية لظاهرة العولمة"، مجلدة دراسات، ليبيا، المركز العالمي لدراسات الكتاب

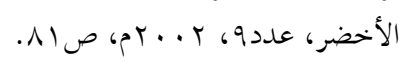

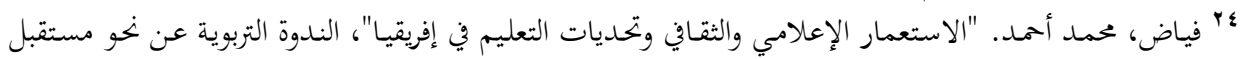

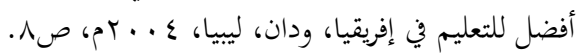


مـلء الوقت المخصص للبـث، لعـدم توافر البرامج، أو لتكلفـة إنتاجها الباهظة، مما أدى بالولايات المتحـدة الأمريكية إلى تقـديم عدد وافر مـن البرامج الثقافية والتعليمية إلى هذه المحطات بحاناً، أو بأسعار رمزية. ولنا أن نحلل طبيعة هذه البرامج الإعلامية ومحتوياها التي تخـدم البراغماتيـة الأمريكيـة بشـكل لا يقـدر بثمن، ولا تسـطيع الجليوش تحقيقهـ لو أهـا

$$
\text { غزت هذه الدول عسكريا. }
$$

وبذلك تشكّل الولايات المتحدة الأمريكية في المرحلة الراهنة القاعدة الأهم، والأكثر تـأثيراً في المشـروع الثتـافي العـالمي بوجهه الاحتكاري، وقدراته الهائلة، وأدواته الإعلاميـة المتقدمة التي لعبـت الدور الحاسم في نشـ الثقافـة الاستهلاكية ذات الطابع التجاري في جميع أنحاء العا لم وترسيخها. بَr وكل ما وقع ويقع كان يهدف إلى تشويه الثقافات المحلية وتمميشها، وإعادة إنتاج البنية الفوقية المختلفة، بما تتضمنه من تسطيح للوعي وتشجيع للمبادرات الفردية القائمة على الأنانية والاستغلال، وانعدام الممارسات العقلانية، وبتث الفوضى والبيروقراطية والرشوة والفساد. rV

إن تعمـيم الـنمط الاستهالاكي الأمريكي الغـربي الـذي تسـود فيـه السـلع الكماليـة والوسائل الترفيهيـة يشكل الهـدف الأساسي الذي تسعى إليه أمريكا بواسطة الاختراق الثقافي، الذي أحلدث آليات الهيمنة العالمية المعاصرة، التي تتوِّج وتستكمل الدور الذي لئي تقوم بـه الشركات متعددة الجنسيات، والبنـك الدولي، وصندوق النقد الدولي، وبحموعـة

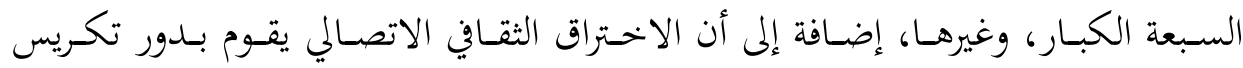
منظومة القيم الوافدة التي تتفاعل داخل المحتمعات النامية والعربية، وتسري ببطء وثبات

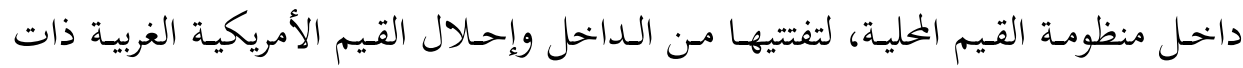
الطابع الاستهالاكي الترفيهي، بهدف إعاقة نمو تلك المحتمعات النامية والعربية المستقلة اقتصادياً وثقافياً واجتماعياً. ^^ويشير "آرجوميدو" Argumedo إلى أن الأخبار المتعلقة

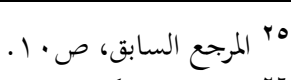

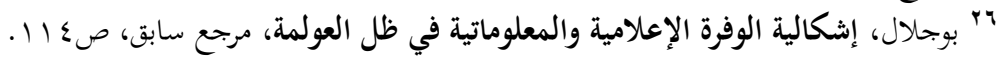

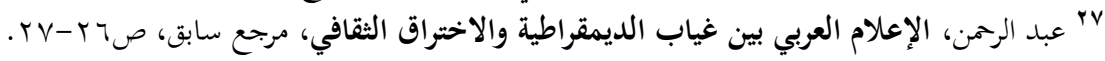

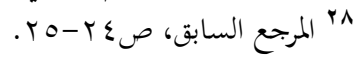


بالشؤون الداخلية والدولية والأفلام وأشرطة الفيديو والبحلات إلخح، تروّج لأنماط من الحمياة

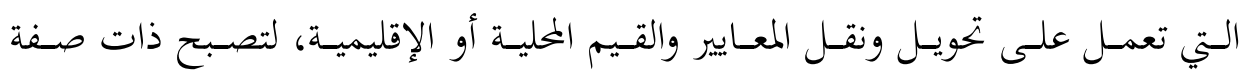
عالمية.

وفي هذا السياق فقد أدّى ظهور البـث الإعلامي المباشر في العالم العربي إلى خلق

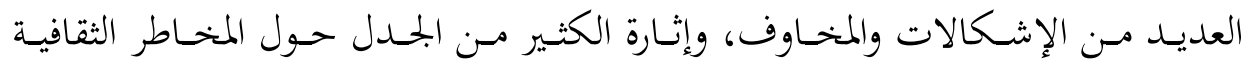
والاجتماعيـة التي ستهـد منظومـة القيم العربيـة التراثيـة والمعاصـرة، مـن خهلال الـبرامج

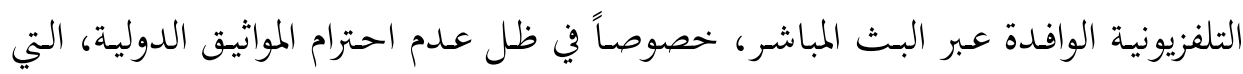

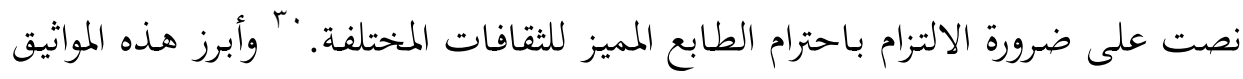

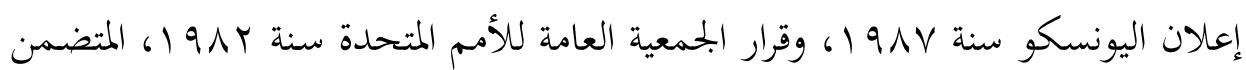

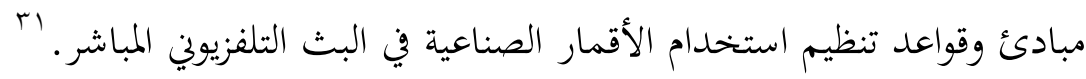
ويلاحظ أن هناك انتهاكاً متواصلاً للدول الكبرى لهذه المواثيق، كما أن استخدام

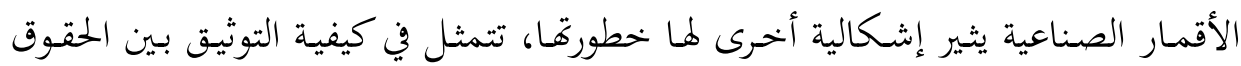

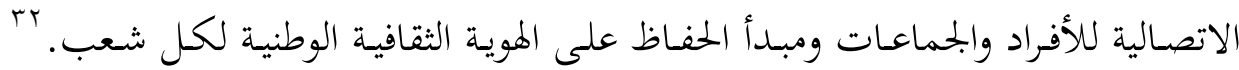

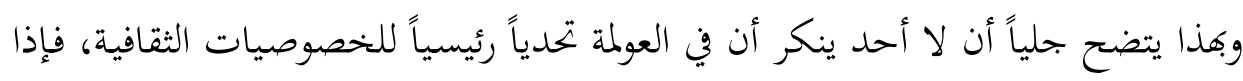

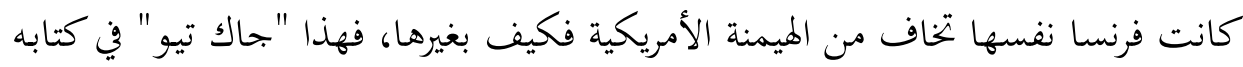

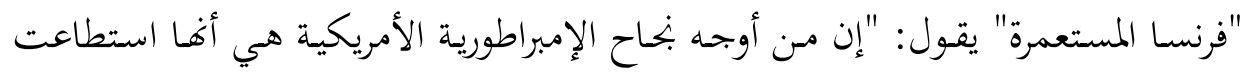

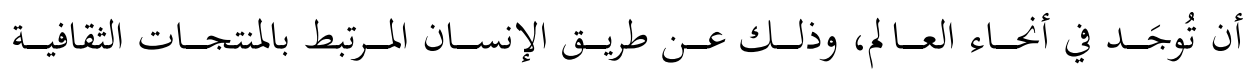

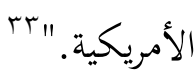

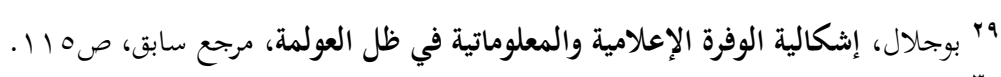

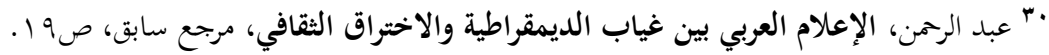

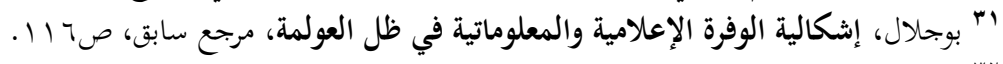

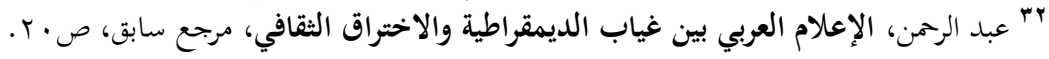

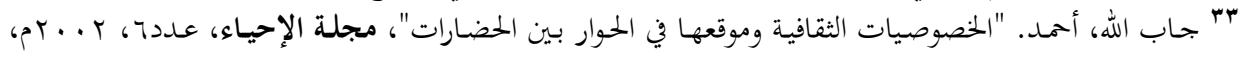




\section{ثالثاً: مشكلات الإعلام العربي في ظل تحديات إعلام العولمة}

أتاحت تكنولوجيا الاتصال أمام الأفراد فرصة هائلة للاختيار بين وسائل ومضامين

كثيرة ومتنوعة، وبهذا ترسخّت فكرة المتلقي النشط القادر على الاختيار، ومنح التأييد أو الرفض أو المقاومة للوسائل أو الرسائل الإعلاميـة، كما بـرزت فكرة دور المتلقي في بنـاء

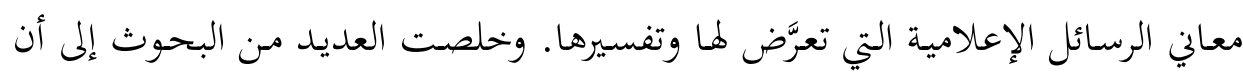
التأثير الإعلامي عملية مقسمة بالتساوي بين منتج الرسائل الإعلامية والمتلقي، إذاكانت عمليات الاتصال والتأثير هي بالأساس عملية ثقافية. ومع التسليم بأن كل فرد هو عضو في جماعة ثقافية، فإن بحوث الإعلام والاتصال التي اعتمدت على مقاربة التحليل الثقافي Cultural Analysis Approach والإعـاملام، فـالأفراد يختـارون ويسـتخدمون وسـائل الإعـام في ضـوء ثقـافتهم، كمـا أن الجمهور ليس بتمعاً بسيطاً للأفراد، بل إن هناك أسساً ثقافية واجتماعية يجب أن تؤخذ بالحسبان عند دراسة عمليات التأثير. كذلك فإن مضمون وسائل الإعلام هو أيضاً منتج

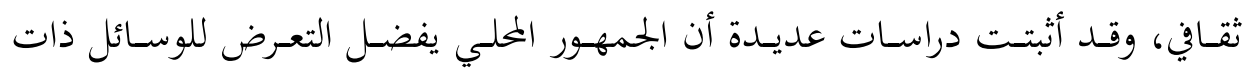
المضـامين المحليـة، لأن المنتجـات الإعلاميـة المحليـة تكـون محميـة - كمـا يقـول "إيثيل دي سولا بول" Ithiel de Sola Pool- عن طريق اللغة والتأييد الاجتماعي وثقافة المجتمع؛ أي إن ما تقدمه يعكس الثقافة المحلية، ويتفق مع مكوناتها الأساسية. ؟ب

ولا يخفى أنَّ الثقافة نفسها مصدر خحلاف مستمر، ذلك أن الثقافة متحصنة، ولا تتغير بسهولة، فالجوانب الجوهريـة للثقافـة ترسـخ مـن خـلال عمليـات تأهيـل اجتمـاعي داخلـ المحتمعات، وبهذه الطريقـة تتغلغل الثقافة عميقـاً في نفسية الفرد، وتتخـذ أساسـاً

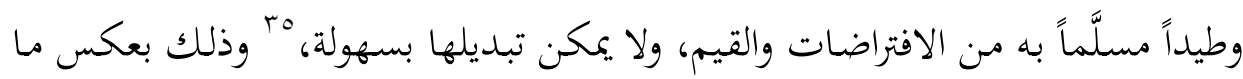

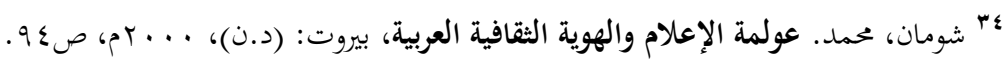

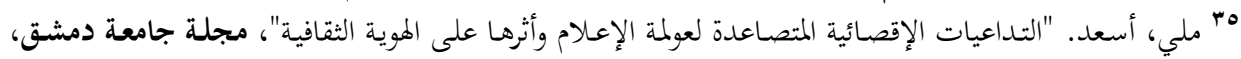


أورده "فوكوياما" في كتابه "التمزّق الكبير"؛ إذ يرى أن الثورة المعلوماتية أحدثت على غرار الثورة الصناعية سابقاً الانحلال في القيم العميقة في البنية الاجتماعية. بَ

لمـذا يـرى بعض المفكرين أنه ليس هنـاك مـا يــل على أن إعـام العولمـة يهـدف بالضرورة إلى محو الهويات الثقافية المعتمدة، لأن العولمة ليست بحاجة لكي تفرض نفسها، وأن تفـرض نظامـاً ثقافيـاً معينـاً على كل أنحـاء العـالم، وأنه مـن المستحيل محو التعدديـة والخصوصية الثقافية، لأن أي شعب له حضارته وقيمه الخاصة به، يستطيع أن ينتقي من الثقافة الأخرى، أما الذي يأخذ ثقافة الآخر بقدرها، فليس عنده أصلاً ثقافة أو حضارة أو قيم. ولا شك في وجاهة هذا الرأي في بعض الجوانب، إلا أنه ينبغي عدم الأخذ به في بحمله، لأن الانتقـاء يتوفر في ظل توافر عـدة شروط، مـن أهمها وجـود البـديل المنـافس، وفك القيود عن حرية التفكير، وتنوير الوعي. وهذا ما جعل الإقبال على الثقافة المستوردة لا يتم مـن خـالال الإيجابيـات والمكتسببات الحضـارية النافعة، وإنما يـتم على حـد تعبير "برهان غليون" Burhan Ghalioun "من خلال فضلات هذه الثقافة."rV"

ويعاني الإعلام العربي من جملة من المشكلات، في سعيه لحماية النسيج الاجتماعي

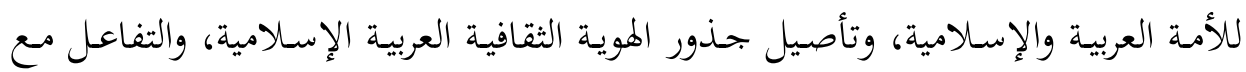
الثقافات الأخرى في ظل إعلام العولمة، غير أن الإحاطة بها ليس من الأمر السهله، وهو إلهو ما يجعلنا نركز على أبرزها:

\section{ا ـ مشكلة تدني الخبرة في فن الإعلام:}

القضية الإعلامية حساسة وفِّالة، والباحث عن دور الإعلاميين العرب يدرك غيابهم

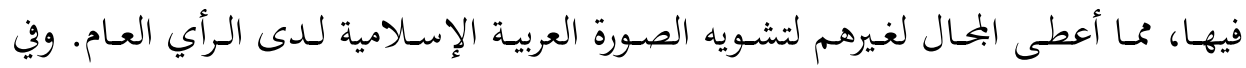

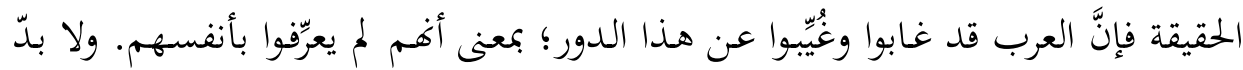

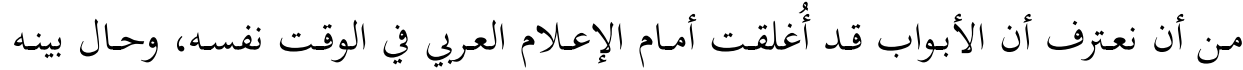




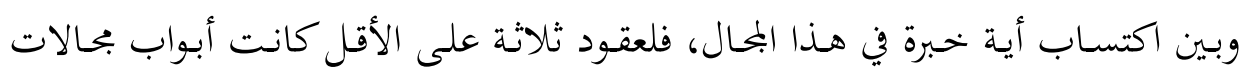

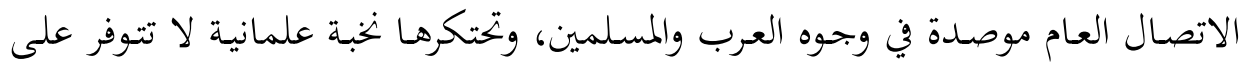
الحمد الأدنى من الولاء للخصوصيات الثقافية العربية والإسلامية، ومن ثمة فإن الإعلاميين

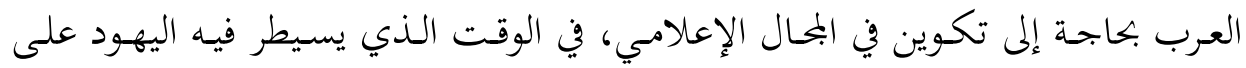

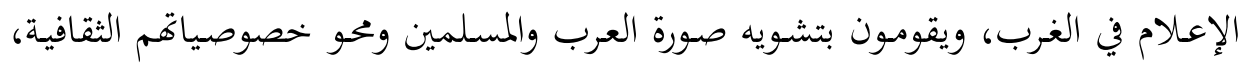

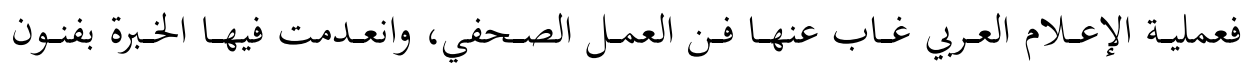

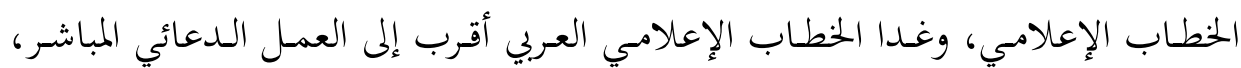

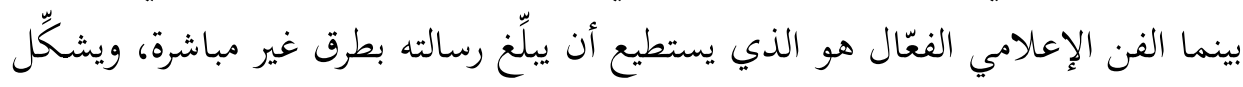

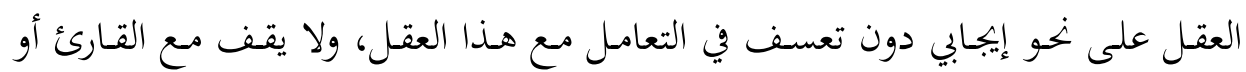

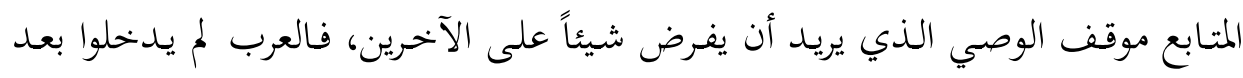

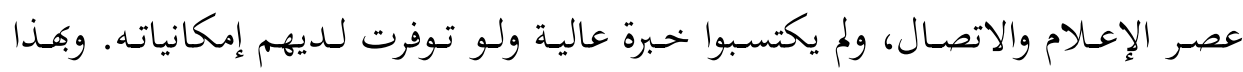

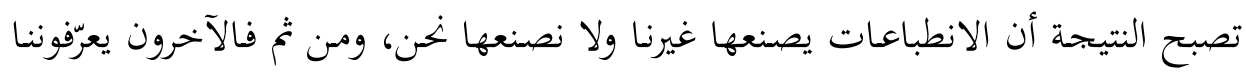

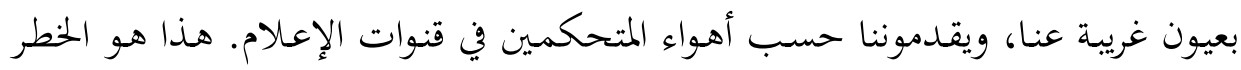

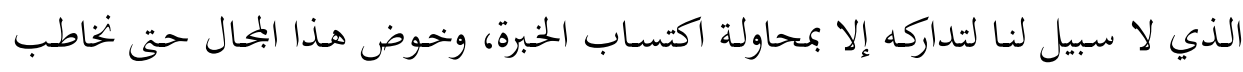

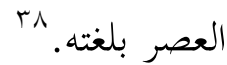

\section{r ـ مشكلة الهيمنة الأجنبية على القنوات الفضائية العربية:}

لقد تم تعويد القنوات الفضائية العربية على تقديم برامج ومواد إعلامية ثقافية أحنبية

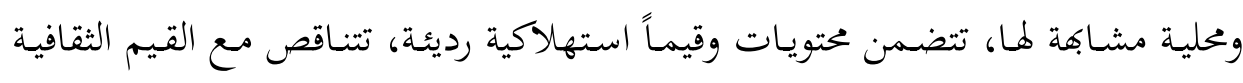
الوطنية، ومع تطلعات الجماهير الشعبية إلى التقدم والتحرر وصيانة مورثوها الثقافي. فلقد

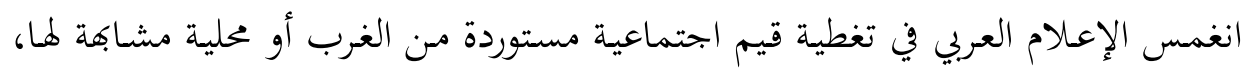

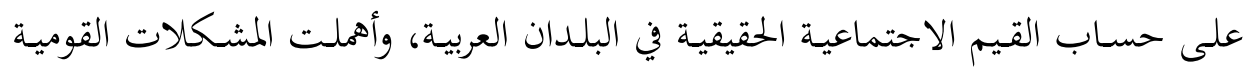

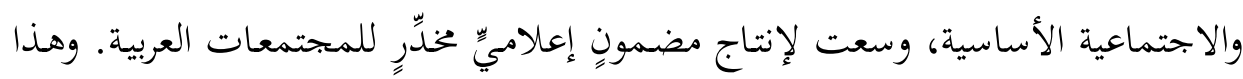

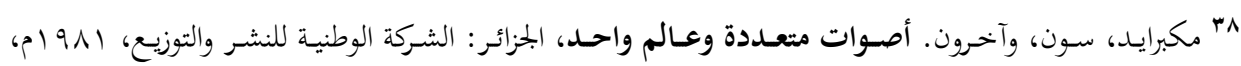


ما أدى إلى غربة المواطن العربي في وطنه، وتشويه قيمه الاجتماعية الأصلية. "جّإِشعاره بأنـه لا صـلة أو لا رابـط بمـا يـراه أو يقـرأه أو يسـمعهد في قـــوات تلفزيونيـة وإذاعيـة ويف صفحات الصحف من مضمون، ويدرك بأن ما تغطيه هذه الوسائل من مضمون هو غير

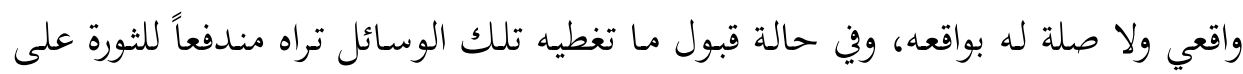

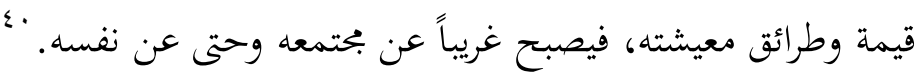

وتبدو الهيمنة الثقافية الأجنبية على القنوات الفضائية العربية واضحة في أدب الخيال العلمـي الغـربي، وذلك بككـم مصـدره اليابـاني -الأوربي - والأمريكـي، فالأسمـاء أكثرهـا أجنبية، وملامح الشخصيات أيضا غريبة عن ملامح الإنسان العربي، ويبدو أن أعمال

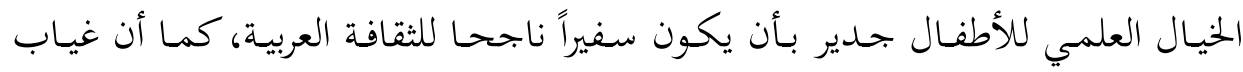
الشخصيات العربية في أعمال الخيـال العلمي العربي التلفزيونيـة والسينمائية ستؤدي إلى

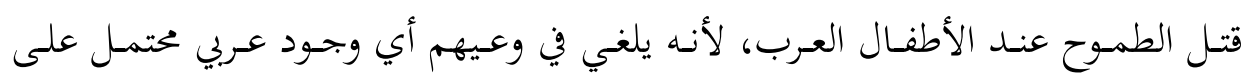
خارطة العالم والمستقبل معاً، فالطفل العربي بذلك يترسب في حسه مع تراكم الأعمال

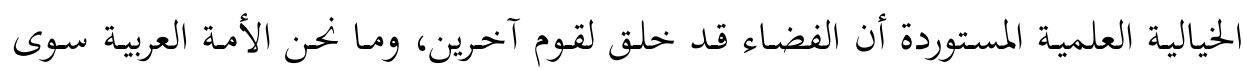
متفرجين ومراقبين لما يحدث نتأثر ولا نؤثر، وليس لنا دور في المستقبل، وانطلقت سفينة

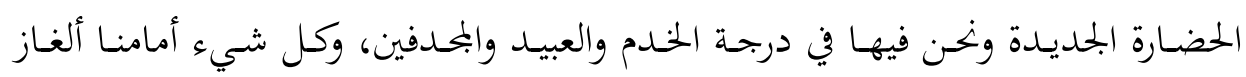
وطلاسـم. فانعدام بطل عربي يُقتَّدى بـه، أو شـصص يتقمص شخصيته... سيؤدي إلى

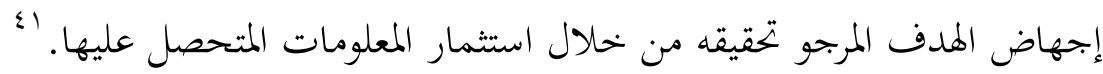
كمـا تبـدو الهيمنـة الثقافيـة الأجنبية على القنوات الفضـائية العربية بكل وضسوح في تغييب الثقافة المحلية، وإحلال غيرها بدلاً منها؛ إذ إن معظم البرامج والأفلام التي تعرضها

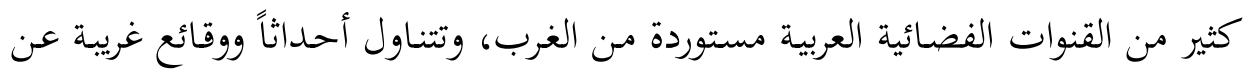
a"r دجاني، نبيل. "البعد الثقافي والاتصالي في ضوء النظام العالمي الجلديد"، مجلة المستقبل العربي، بيروت، لبنان،

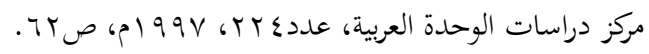

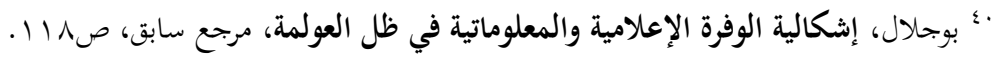

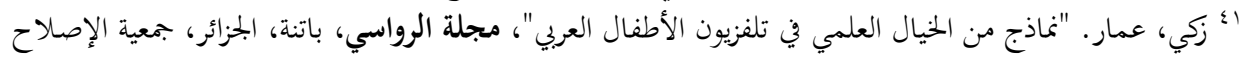

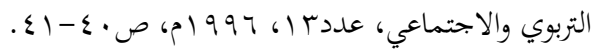




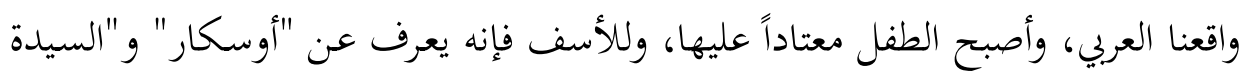

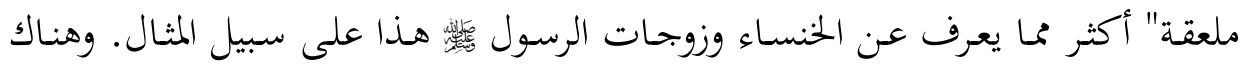

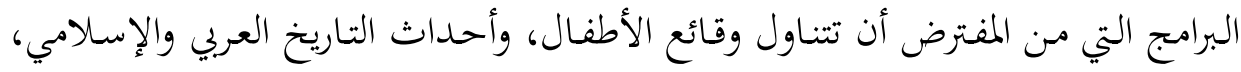

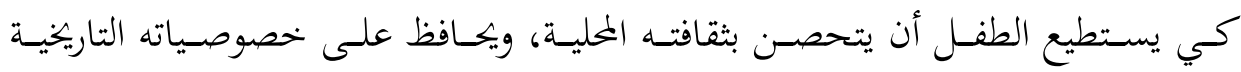
والجغرافية.

ومع أن الحضـارة العربية والإسـلامية سـجّلت للتـاريخ الإسـلامي لواء المعرفة بنمـاء

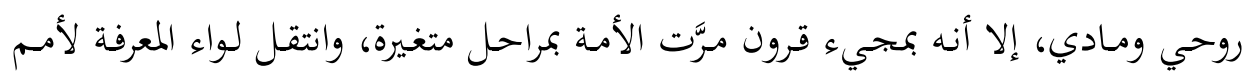

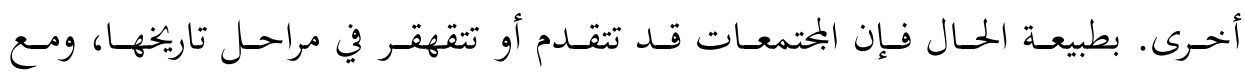

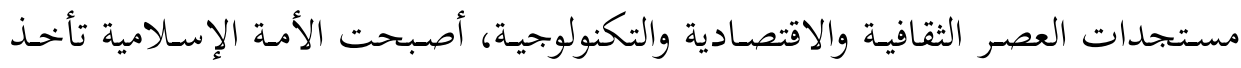

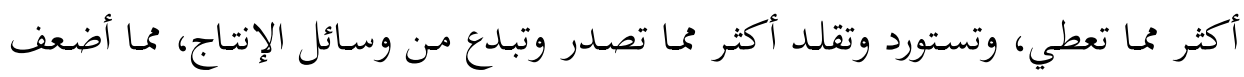

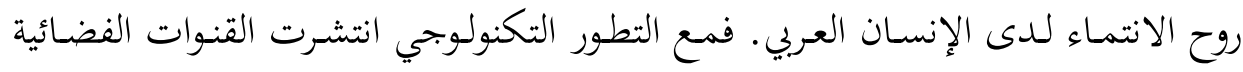

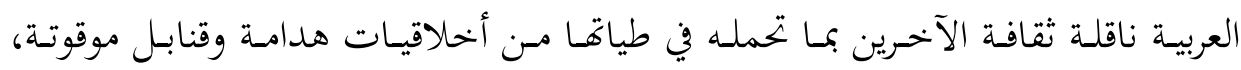

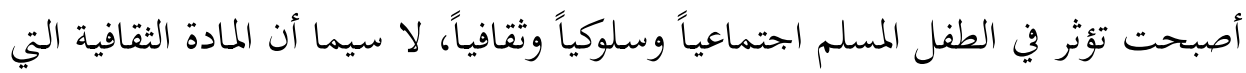
تبثها القنوات الفضائية أصبحت بحـذب حواس الإنسان وقدراته بعامَّة، وليس الطفل

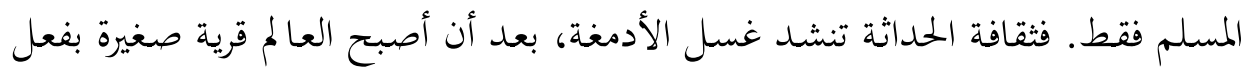

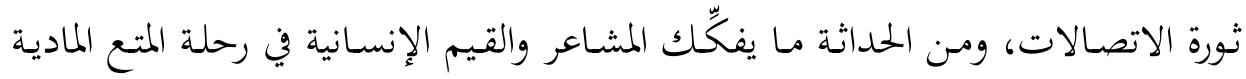
الزائفة، التي تمنح العقل الإنساني معايشة الغيبوبة.

\section{r. اككلة تحديات حرية الإعلام:}

تطرح حرية الإعلام نفسها إشكالية ذات أوجـه متعددة. ويشير عضو هيئة تحرير

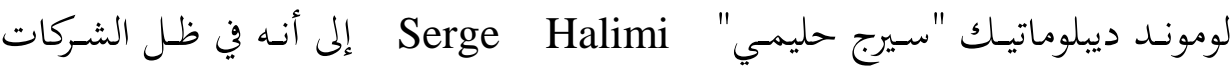

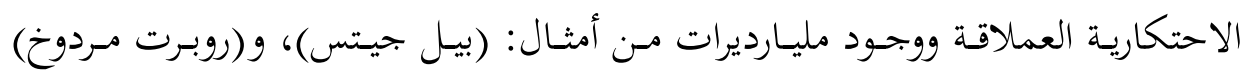

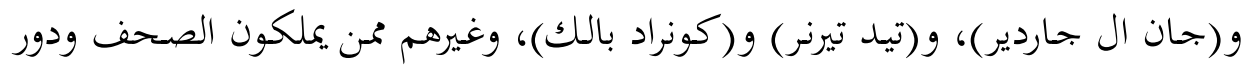

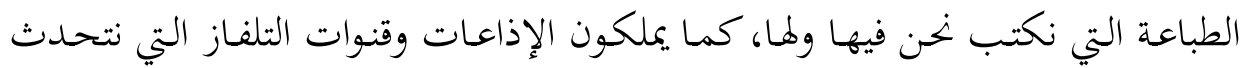


ونظهر فيها؛ وبتعبير آخر؛ في مثل هذا العالم الشمولي الكلياني، وهذا الكون الإجمالي، هل ما نزال نحن -الصحفيين والمفكرين - قادرين على أن نؤدي دورنا المعارض للسلطة،

$$
\text { وأن نكون صوت من لا صوت لهم. }
$$

كل هذا وغيره يكشف عن الأوجه المختلفة لإشكالية حرية الإعلام، فثمة مخاوف وتحديات تتعلق بمدى قدرة وسائل الإعلام والاتصال الحديثة المرتبطة بالشركات الإعلامية

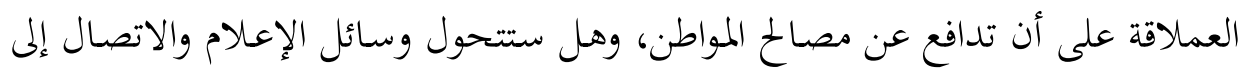

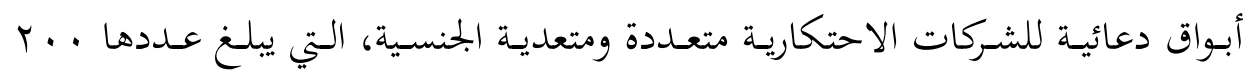
شركة، وتسيطر على أكثر من · بـ\% مـ الإنتاج المحلي الخام في العالم. في هذا الإطار

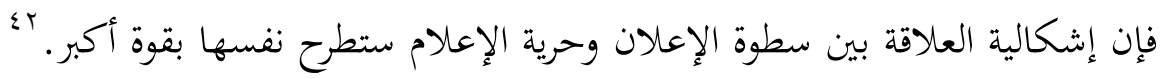

\section{ع. مشكلة الانقسامات الداخلية:}

ونقصـد بـذلك الانقسـام داخـل المجتمعـات العربيـة بـين نخـب قـادرة على استخحدام تكنولوجيـا الاتصـال والإعـلام والمعلوماتيـة، والاسـتفادة منهـا؛ أي نخـب معولمـة إذا جـاز الوصف، وأغلبيـة غير قـادرة على ذلك، ومهمشـة اجتماعياً واقتصـادياً وإعلامياً، وربمـا

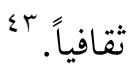

رابعاً: سبل المواجهة والتصدي والبديل المؤهل لذلك ا ـ سبل المواجهة واستراتيجيات التصدي:

مـن أجـل مواجهـة إعـلام العولمـة والتصـدي لـه وفضـح مقاصـده، لا بـدّ مـن تبـني استراتيجية بعيدة المدى ومتعددة الجوانب، وتخصيص الإمكانيات المادية اللازمة لتنفيذها. وما يجب أن يكون في مقدمة أولويات هذه الخطة هو تحصين الشبان، وذلك بتعبئتهم سياسياً وتقافياً وروحياً، وتوعيتهم بالأخطار التي يستهدفها إعلام العولمة، والبدء في صنع

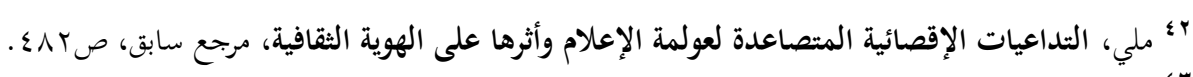

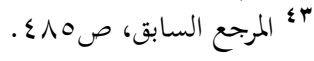


الإعلام المحلي البديل، الذي يلبي حاجات شبابنا النفسية، ويتوافق مع قيمنا وتراثنا الديني

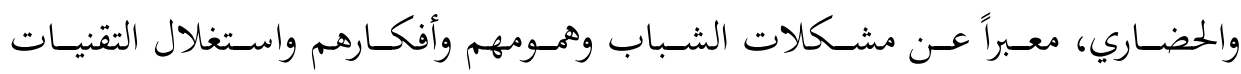
الإعلامية الحديثة القـادرة على استقطاب الشباب، وإبعادهم عن رذائل الإعلام الغربي، وإعطاء الفرص للشباب للمشاركة في صنع المادة الإعلامية، والتعريف بثقافتهم والبحث عن الأسباب العميقة التي تجعلهم يتهربون من وسائل الإعلام المحلية إلى الإعلام الغربي،

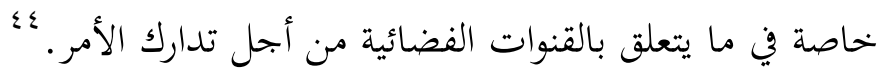

ولا بدّ لمذه الاستراتيجيات المتبناة في الميدان من أن تشغل خختلف مؤسسات التنشئة

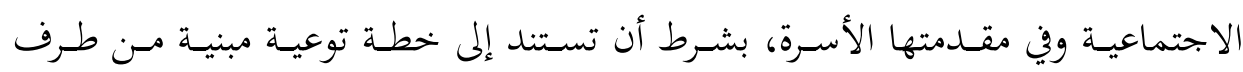
متخصصين في بحال التربية وعلم النفس وعلم الاجتماع وغيرها، ومتمتعين بدرجة عالية

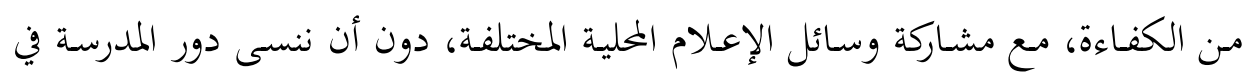
المراحل التعليمية المختلفة، وخحاصة في مرحلة التعليم الثانوي والجمامعي لقدرقما في هذه المرحلة على المزج الحضاري الذي تبين فيه بكل موضوعية الإسهامات العربية والإسلامية في العلوم والفنون.

ومن السُّبل الكفيلة بذلك -أيضاً- تحجيم الغزو الثقافي الغربي، وحصره في أضيق الحـدود الممكنة، وبـلك يتسنى تخفيـف حدته وإضعاف فاعليته، عن طريق الإشـراف الواعي والمباشر على كل ما ينشر ويبث في مختلف وسائل الإعلام الأجنبية. ولا نقصد

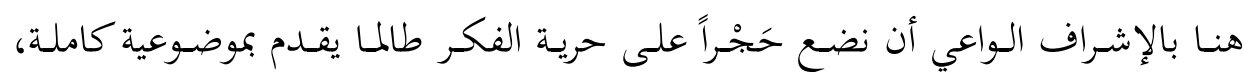
فبهذه الإجراءات البسيطة وغيرها تصبح وسائل الإعلام المختلفة أدوات للتربية، ورعاية الشباب، ووسائل للمحافظة على الخصوصيات الثقافية لكل دولة، أمـا إذا ترك الحبل على الغارب لهذه الوسائل والأدب الرخيص والفن الماجن الخليع، وأداة للترويج للجريمة والرذيلة، فإننا لن ننتظر من هذه الوسائل إلا أن تكون أداة هلدم عقائد الشباب وتشويه تفكيرهم وتلويـث أخلاقهم، وتـدمير شخصـيتهم الإسـلامية ومحو معالمها، مما يستدعي

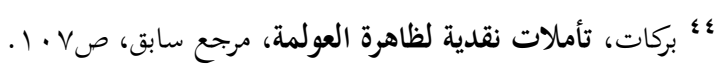

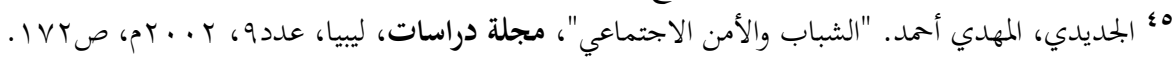


انفتاحاً ثقافياً واعياً على العالم، مرتكزاً على الخصائص الفكريـة والوجدانيـة لهذه الأمـة، وعلى أصالتها الثقافية، وهـذا يتطلب بنـاء السياسـة الثقافية على تخطيط سـليم للتبـادل

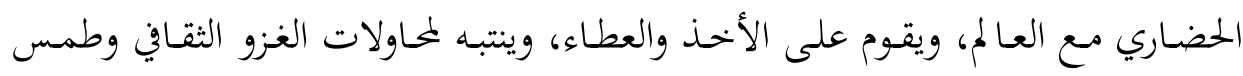

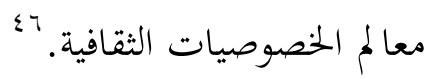

فمن واجب الأمة أن تحمي خصوصياقا الثقافية وتدرأ عنها الأخطار التي تمدها أياً كانـت، ولا يجــوز أن يكـون ذلـك بـالانغلاق والتقوقـع، كمـا لا يكـون بالانفتـاح غـير المشروط ولا المدروس، لأن النتائج الناجمة عن ذلك وإن لم قهدد وجود الأمة فإهـا خطيرة جداً على البنية الفكرية والثقافية والاجتماعية، وقد تترك من الآثار السلبية ما يحتاج إلى

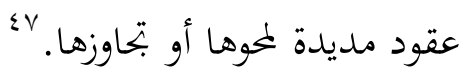

وفي هذا السياق قامت إيران والصين وسنغافورة بتجربة التخطيط الناجحة، بالسعي بقوة لتقييد وصول برامج الحاسوب إلى مواطنيها، وهـفها هو إبعاد مـا يبثه الأمريكيون

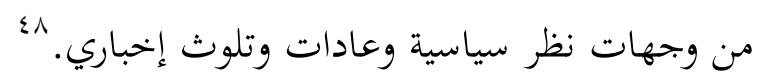

إن هذا السلوك كما يذكر عزت السيد أحمد -على عدم صوابيته المطلقة- فإنه قد

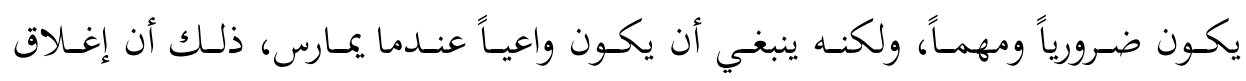
الأبواب والمنافذ أشد خطراً من فتحها.

والوعي المطلوب هو الوعي الحقيقي لا الوعي الزائف. فالوعي الحقيقي هو الذي يؤدي إلى تحقيق الانتماء؛ إذ إن الوعي الصادق هو الوعي الذي ينتج هويته ولا يتلقاها

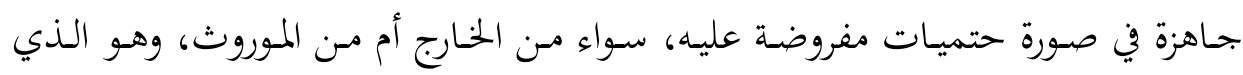

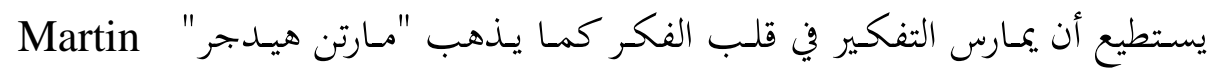

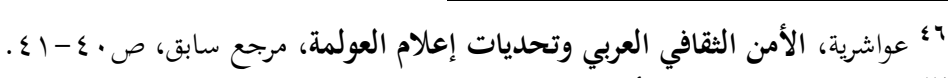

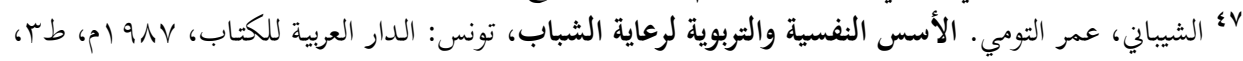
ص700.

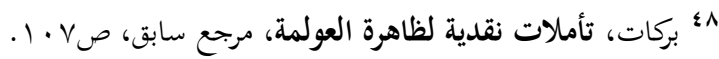

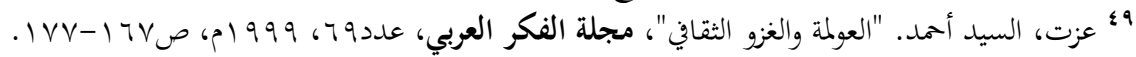


ما دام كل فكر متشكل فكراً قد تموضع بالفعل وتحول من مرحلة الحركة والممارسة الإبداعية إلى حالة الثبوت والسكون. •

إن التفكير بإمكانيـة وجـود المتلقي النشط أو المتلقي الـواعي القـادر على اختيـار

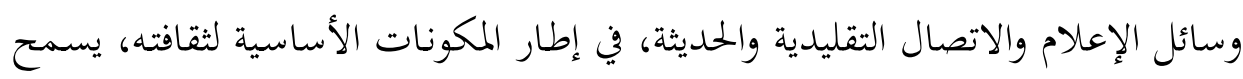

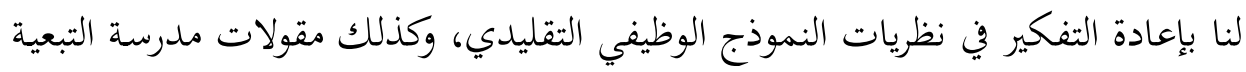

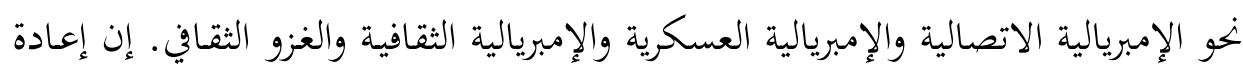

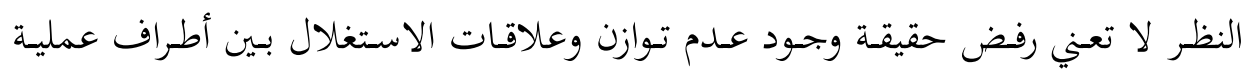

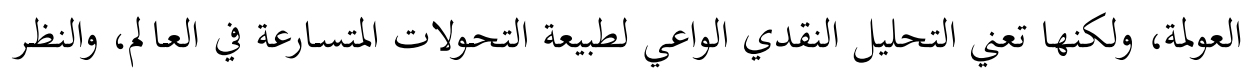

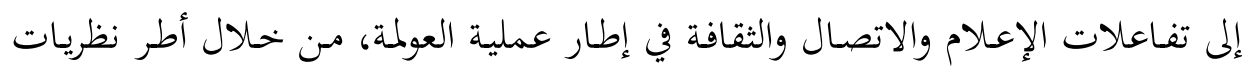

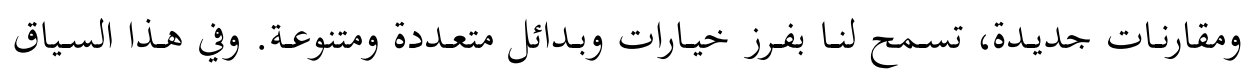

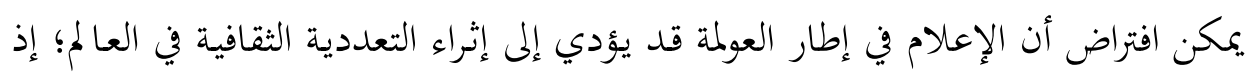

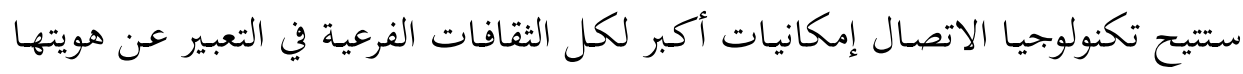

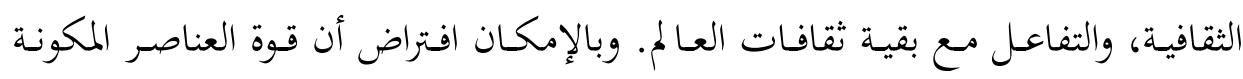

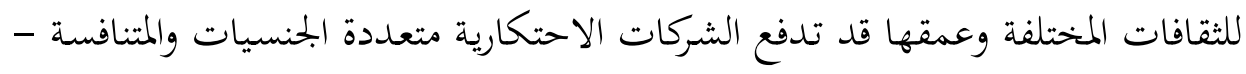

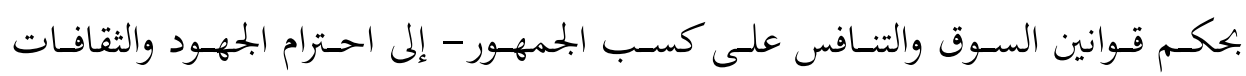
المختلفة، وتقديم مضامين وصور تحترم هذه الثقافات.

ومواجهة تحديات إعلام العولمة ورسم صورة المستقبل الجلديرة بخصوصياتنا الثقافية

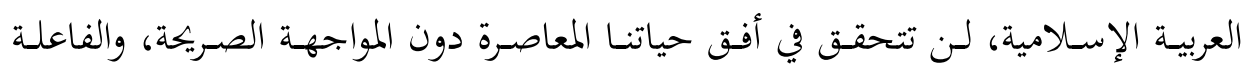

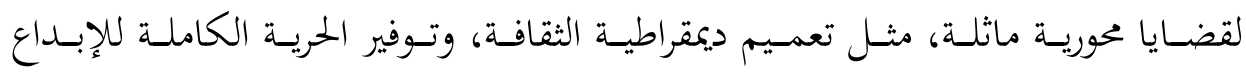
والمبدعين، وضرورة الربط العضوي بين التنمية الثقافية والاجتماعية والاقتصادية، إضافة

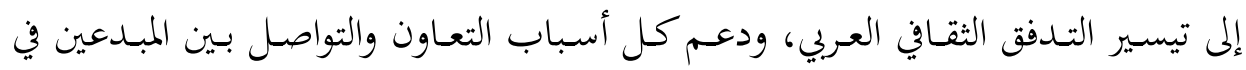

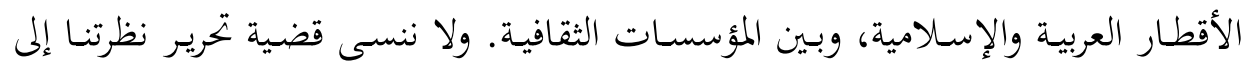


تراثنا الثقافي وربطه بحاضرنا، وتوظيفه كقوة تعزز هويتنا الثقافية في مواجهتها لتحـديات إعلام العولمة. ro فضلاً عن ذلك، فإن خصخصة وسائل الإعلام العربية والسماح للقطاع

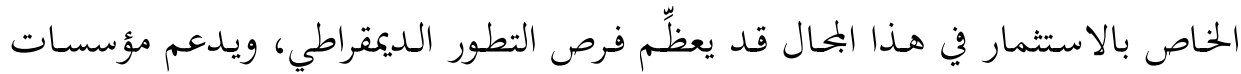

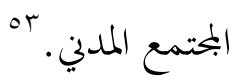

\section{Y ـ البديل الإعلامي العربي المؤهل للتصدي لتحديات إعلام العولمة:}

كل مـا سبق يبرز بـلا شك حاجتنا إلى إعلام بـديل، يعيد بناء مـا قد سبق هدمهـ وتخريبه، وإلا فإنــا نـــر بكارثتة مروعـة لا تبقى ولا تـذر، تشــمل عقيـة الأمـة وأخهلاق شبابها ومسيرتا في التاريخ. فما البديل؟ إنه في رأينا الإعلام العربي الإسلامي الحر.

فما المقصود بالإعلام العربي الإسلامي الحر؟ وما السُّبل المؤدية إلى تحقيقه؟

\section{أ. أإعلام الإسلامي الحر :}

الإعـام الذي نرى فيه علاجـاً لمشكاتلات إعلامنـا العربي هـو ذلك الإعـام الذي يتخذ من عقيدة الأمة وثوابتها الراسخة منطلقاً أساسياً في إعداد البرنامج، وبث الأخبار وتوجيه الحصص (البرامج) والأنشطة الإعلامية المختلفة وجهة تخدم الأمة، وتعرّقها بدينها

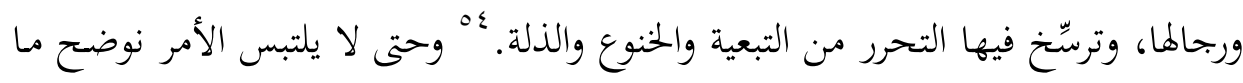
نعنيه بالإعلام الإسالامي الحر:

لا نقصد بـالإعلام الإسـالامي الحـر مـا يعرف اليوم بالإعلام الديني الذي يتمثل في خطب المساجد والصفحات الدينية والإذاعية والتلفزيونية، والمسلسلات والأفلام الروائية الدينية، فهذه الأمور كلها جزء بسيط مما يقوم به الإعلام الإسلامي من أعمال. فالذي

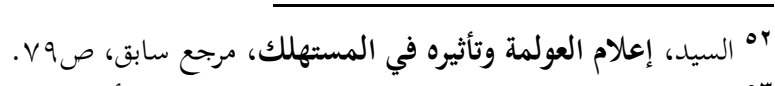

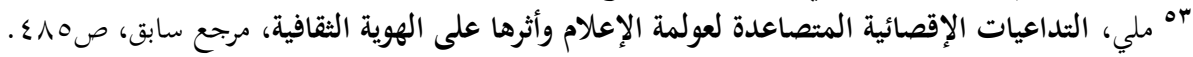

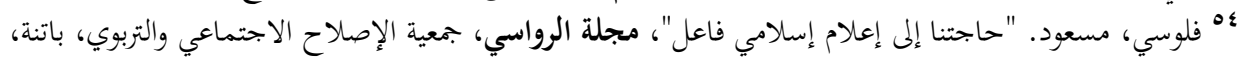


نقصده من مصطلح الإعـلام العربي الإسـلامي الحـر هو ذلك الإعـلام الذي تسري فيه

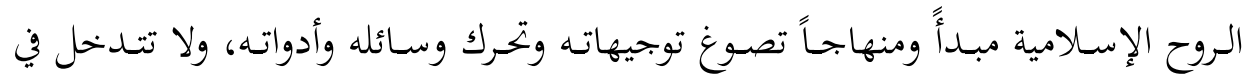
توجيهه قوى أخرى حتى تقيده وتتسلط عليه، ولا يهم بعد ذلك نوع العمل الإعلامي، مقروءاً كان أو مسـموعاً أو مرئيـاً؛ إذ لا فائدة مـن برنامج ديني تقدمـه امرأة متبرجـة، أو رجل تبدو عليه مظاهر التغريب، وسمات الانحلال.

ب. السُّبل المؤدية إلى تحقيق إعلام عربي إسلامي حر: يتطلـب تحقيـق الإعـلام الإسـلامي الحـر العديـد مـن الإجـراءات، نوجزهـا في النقـاط الآتية:

1 ـ ميدان الإعداد والتأهيل البشري: وذلك بإعداد الكفاءات البشرية المتخصصة

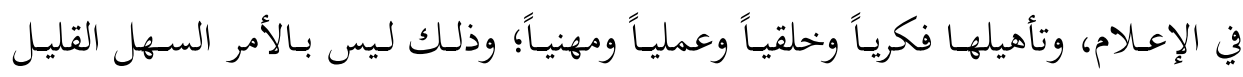
التكاليف، بـل هو عمل كبير يتطلب جهوداً عظيمـة وطاقات ضـحمة. ولا بـد لإعـداد الإعلامي العربي الإسلامي وتأهيله من أن يتكامل في الجوانب الآتية: - الإعـداد الأصـولي والفكــي: مـن خـلال تعريفـه بالأصـول العقديـة والفكريـة والتشـريعية للإسـلام؛ وذلكك بوسـاطة بحموعـة مختـارة مـن المقـررات الشـرعية والفكريـة في القرآن الكريم والتوحيد والتفسير والحديث والفقه والثقافة الإسلامية.

- الإعـداد اللغـوي والتـذوقي: بتدريبه على بعض المقـررات في اللغـة نـواً وصـرفاً وفقهاً، وتمكينه من فنون القول والبيان والتعبير، والأسلوب الإعلامي والتذوق الأدبي. - الإعـداد التخصصي والمهني: وهنـا لا بـدّ من أن يتكامل فيه الجانب النظري والجحانـب العملي التطبيقي، ولا بـدّ مـن اكتسـاب المتمهـن الإعلامي للمهارات العلميـة والمهنية المطلوبة منه في واقع الممارسة الميدانية.

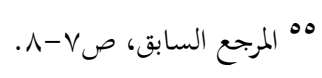


- الإعلداد الثقافي العام: وهذا يتطلب الإلمام بالواقع الذي يعيش فيه مـ حيث قضاياه ومشكلاته وأحداثه وتياراته، كما يتطلب الإلمام ببعض المعارف والعلوم المعينة له على فهـم هـذا الواقع وتحليله، وهي علدوم وثيقـة الصـلة بـالإعلام، كعلـم الـنفس وعلـم الاجتماع والعلوم السياسية والاقتصادية واللغات الأجنبية.

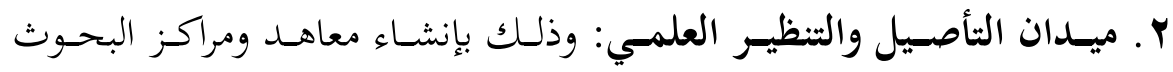
الإعلاميـة العربيـة ودعمهـا، حستى تـؤدي مـا هـو داخـل في اهتماماتهـا بـالإعلام العـربي الإسـلامي، واستقطاب البـاحثين والدارسـين الـذين يتميزون بـالإخلاص والـوعي العـربي الإسلامي والخلفية الشرعية، والاستيعاب العلمي للتخصص الإعلامي، إلى جانب تمتعهم

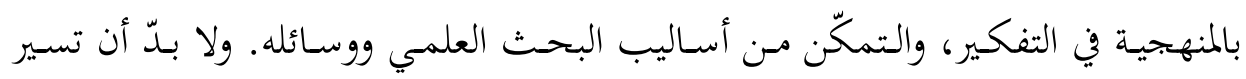

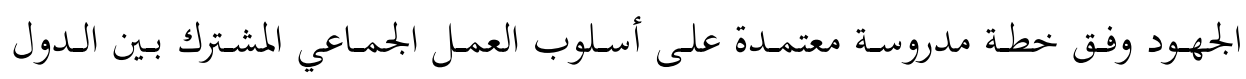
العربية، وملدعمة بإمكانات مادية وبشرية ملائمة.

ץ. ميسـدان الإصـالاح الـواقعي: وذلـك بالإسـهام الإيجـابي في إصـلاح أوضــاع

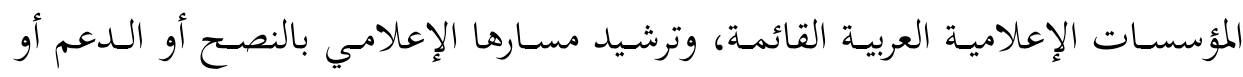
المشـاركة العملية. ويبـأ ذلك بمحاولة إيجاد قنوات تواصل وتعاون بين المهتمـين بشؤون الـدعوة والإعـام الإسـلامي على المسـتوى الـوطني والـدولي العـربي، والعـاملين في المحال الإعلامي، من أجل تضييق الفجوة بينهم. ع. ميدان الإنتاج العلمي المتميز: لا بـدّ لذلك مـ المبادرة إلى إنشاء مؤسسات وشركات عربية إسلامية للإنتاج والتوزيع الإعلامي في مختلف البحالات (طباعة وصحافة ونشر وتلفزيون وفيديو وتسجيلات صوتية وشرائح مصورة وأفلام سينمائية) وغيرها، وهذا يتطلب طاقات بشرية عديدة، وتكاليف مادية باهظة. فهذا الاستثمار سيعود بمكاسب مادية ومعنوية لا نظير لها. أمـا في مـا يخص حرية الصحافة فهي مشكلة لم ينته النزاع

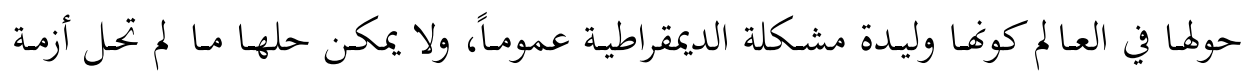
الديمقراطية برمتها في المجتمع كله. 
خاتمة:

تلخصت الفكرة الأساسية الإجمالية لمذا البحث في التعريف بأثر إعلام العولمة في

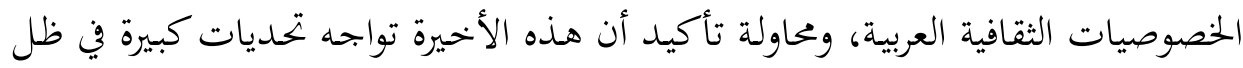

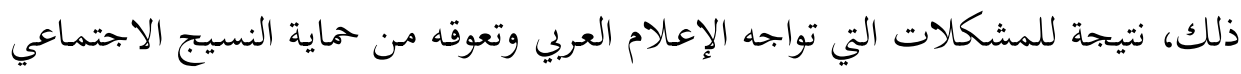

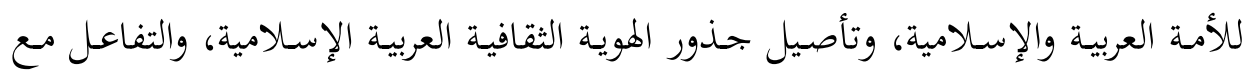
الثقافات الأخرى في ظل إعلام العولمة.

وأوضحنا تصـوراً جديداً لاستراتيجيات مواجهة تلكك التحـديات، واقترحنـا البديل

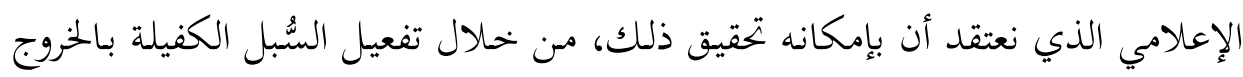

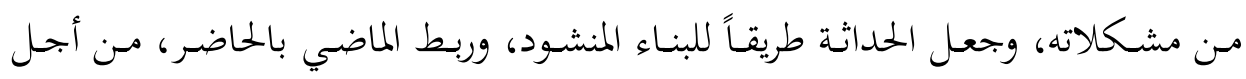

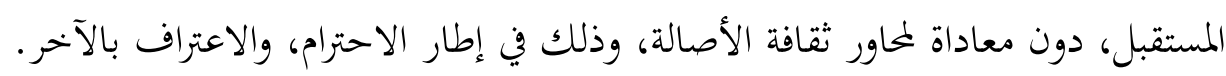
أما عن التطبيق العملي للبديل الإعلامي المقترح، فليس في الواقع العربي والإسلامي

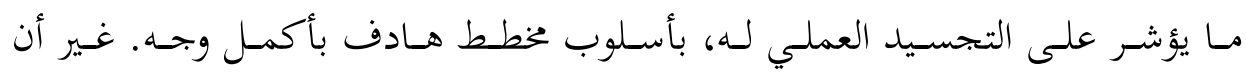
المستقرئ للجهود المبذولة من طرف بعض التجارب الإعلامية العربية والإسلامية في هذا

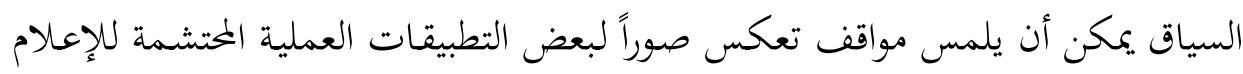

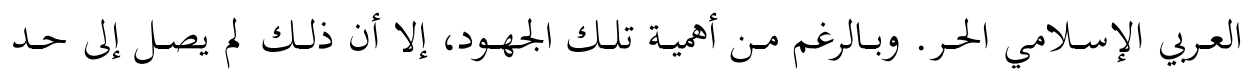

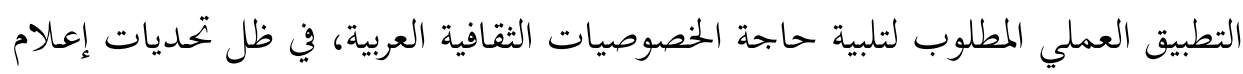

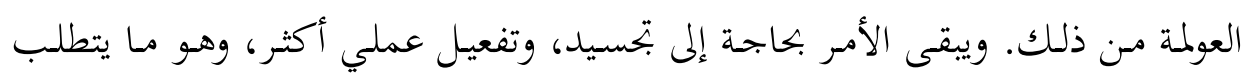

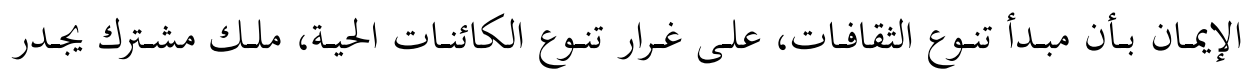

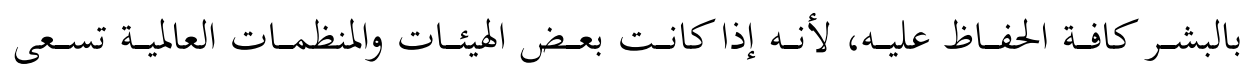

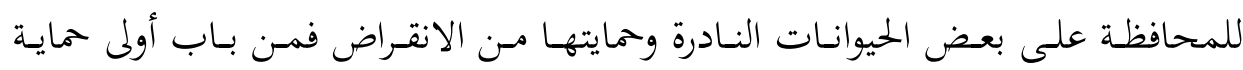
التراث الثقافي والخضاري من ذلك مهما كان صاحبه.

لقد عانينا على مر التاريخ من الهيمنة الثقافية بشتى أنواعها، ولا يزال الغرب يكثّف

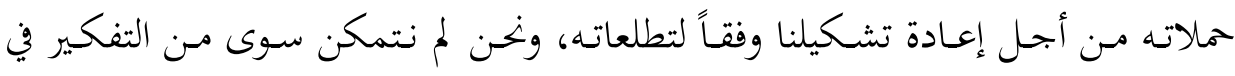



حـدود تيـارات الانغـلاق أو الذذوبان في الآخر، وهما خيـاران ليسـا في صالحنا. وملاكان إعـالام العولمة حتميـة لا مفـر منهـا، فإنـه يتعـين على الشعوب أن تتضـامن في مـا بينها

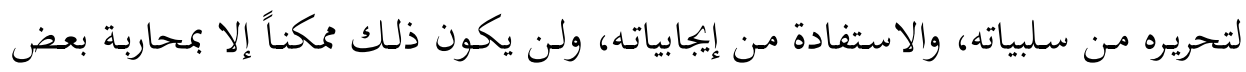
السمات التي أصابت الشخصية العربية بالاغتراب، واستهلاك قشور الحضارات الأخرى

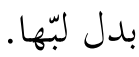

لذلك فإن الموقف الصحيح الذي نراه أكثر وجاهـة بحاه إعلام العولمة، لا يتجسد بالاندماج المطلق والاستجابة لكل مقتضياته، ولا بالانزواء والرفض والاتحام لكل تحلياته، وإغنا يتجسد ويفعَّل من خلال إدارة العملية الثقافية والاقتصادية والإعلامية بالتواصل مع

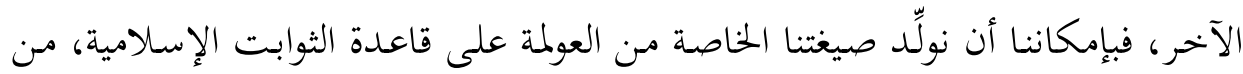
خلال إعلام بديل عربي إسلامي حر. 